\title{
FIGNL1 promotes non-small cell lung cancer cell proliferation
}

\author{
MIAO LI ${ }^{1,2^{*}}$, YAN RUI $^{3 *}$, WENJIA PENG ${ }^{4 *}$, JUNFENG HU $^{3 *}$ \\ ANBANG JIANG ${ }^{3}$, ZEYU YANG ${ }^{3}$ and LINIAN HUANG ${ }^{3,5}$
}

\begin{abstract}
${ }^{1}$ Department of Respiratory Medicine, Anhui Provincial Hospital, Cheeloo College of Medicine, Shandong University, Jinan, Shandong 250021; ${ }^{2}$ Department of General Medicine, The First Affiliated Hospital of Bengbu Medical College, Bengbu, Anhui 233000; ${ }^{3}$ Department of Respiration and Critical Care Medicine, Anhui Provincial Key Laboratory of Clinical Basic Research on Respiratory Disease, The First Affiliated Hospital of Bengbu Medical College, Bengbu, Anhui 233004; ${ }^{4}$ Department of Epidemiology and Health Statistics, Bengbu Medical College, Bengbu, Anhui 233030;

${ }^{5}$ Department of Respiratory Medicine, Anhui Provincial Hospital, Hefei, Anhui 230000, P.R. China
\end{abstract}

Received January 4, 2020; Accepted August 31, 2020

DOI: $10.3892 /$ ijo.2020.5154

\begin{abstract}
Lung cancer is the most frequently diagnosed cancer and the leading cause of cancer-associated mortality worldwide. In the present study, a novel molecular therapeutic target for lung cancer was investigated. The protein expression level of fidgetin-like 1 (FIGNL1) in human lung cancer tissues was determined and its potential functions in the H1299 and A549 lung cancer cell lines was subsequently studied. In addition, the protein expression level of FIGNL1 in 109 lung cancer samples and corresponding para-cancerous tissues was investigated, using immunohistochemical staining. RNA interference and overexpression of FIGNL1 was used to determine the role of FIGNL1 in regulating cell proliferation, and cDNA microarray analysis was performed to identify the potential regulatory pathways. Lastly, the potential role of FIGNL1 in regulating tumorigenesis in lungs and also the proliferation of lung cancer cells was investigated. Firstly, lung cancer tissues were found to express higher protein levels of FIGNL1 and was significantly associated with decreased cell proliferation, migration and invasion abilities, and enhanced
\end{abstract}

Correspondence to: Dr Linian Huang, Department of Respiration and Critical Care Medicine, Anhui Provincial Key Laboratory of Clinical Basic Research on Respiratory Disease, The First Affiliated Hospital of Bengbu Medical College, 287 Changhuai Road, Bengbu, Anhui 233004, P.R. China

E-mail: hlnbbmc@163.com

*Contributed equally

Abbreviations: CCK-8, Cell Counting Kit-8; FIGNL1, fidgetin-like 1; GO, Gene Ontology; KEGG, Kyoto Encyclopedia of Genes and Genomes; MCM, mini-chromosome maintenance complex; NSCLC, non-small cell lung cancer; PCNA, proliferating cell nuclear antigen; SKP2, S-phase kinase associated protein 2

Key words: FIGNL1, lung cancer, cell proliferation, cell cycle, apoptosis cell death. Overexpression of FIGNL1 significantly promoted cell proliferation, including decreased arrest at the $G_{1}$ phase of the cell cycle and apoptosis, as well as increased ability for fission and migration. These in vitro findings were consistent with the results of the cell-line derived xenografts in BALB/c nude mice, where tumor growth was decreased when injected with cells transfected with shFIGNL1. Collectively, these results provide suggest that FIGNL1 is involved in cell growth and tumorigenesis.

\section{Introduction}

Currently, lung cancer is the most frequently diagnosed cancer $(11.6 \%$ of total cases) and the leading cause of cancer-associated deaths (18.4\% of total cancer deaths) in 2018, worldwide (1). The estimated 5-year survival rate of patients with lung cancer is $\sim 15 \%$ (1). In addition, of the patients who are diagnosed with lung cancer, $80 \%$ are typically diagnosed with non-small cell lung cancer (NSCLC) (2); therefore, a comprehensive understanding of NSCLC is urgently required. Lung cancer is typically diagnosed at a late stage, due to its insidious nature, and surgical resection is not available as a suitable treatment option. Currently, tyrosine kinase inhibitors (such as gefitinib and erlotinib) are the most commonly used drugs for treatment of lung cancer (3). However, the development of tolerance and the side effects of these drugs are key challenges in clinical practice (4). Therefore, an improved understanding of the molecular mechanisms involved in tumorigenesis in lung cancer is required in order to identify novel molecular markers to improve the therapeutic effect.

In our previous study (5), it was found that FIGNL1 was regulated by the HIST1H3D gene, which is located on chromosome 6 and encodes histone H3.1 of the H3 class of histones in humans. Previous studies have also shown that mutations in histones (epigenesis shift) may lead to shifts of the chromatin state and induce cancerous changes (6,7), as higher transcriptional activity requires a less compact state of chromatin (8). In previous biomedical research, HISTIH3D was associated with gastric (9) and lung cancer (5). On the other hand, FIGNL1 
was found to be an important regulator of cell proliferation and the cell cycle $(10,11)$, which negatively regulates the apoptotic process (12).

FIGNL1 is an important member of the ATPase Associated with diverse cellular Activities (AAA-ATPase) group and plays an important role in regulating animal developmental morphogenesis (13). The N-terminal of AAA-ATPases was found to be responsible for its localization on the centrosomes, while the AAA domain at the C-terminal is hypothesized to drive diverse cellular functions, such as interactions with cofactors or nucleotides (14-16). As a molecular chaperone, AAA-ATPase participates in a wide range of cellular regulatory progresses, such as protein folding and degradation, bio-synthesis of organelles, and vesicular transport and cytoskeleton maintenance $(16,17)$. According to a previous study, FIGNL1 was found to be primarily localized in the nucleus (18), in addition it has been found to be involved in numerous biological processes (19-23). With respect to its basic functions, FIGNL1 participates in hydrolase, ATPase, microtubule-severing activities (19-21), and regulation of double-strand break repair by homologous recombination (18). In vivo experiments indicated that FIGNL1 maintains the stable structure during microtubule depolymerization and remodeling of chromosome axis protein (18); this in turn affects meiotic nuclear division in male rats, and causes decreased weight of male mouse testes (22). Skeletal anomalies have also been found in mice lacking fignll (23), which suggested that the FIGNL1 gene may play a key role in regulating systemic development.

However, to the best of our knowledge, the biological mechanisms by which FIGNL1 regulates cell proliferation have not yet been elucidated. With respect to diverse range of functions of FIGNL1, to drive normal cellular activities, FIGNL1 mutations may lead to abnormal cellular behaviors. The present study hypothesized that FIGNL1 could also be an important regulator in the development of lung cancer and has been associated with the proliferation of lung cancer cells (24). Therefore, the aim of the present study was to identify the molecular mechanisms in which FIGNL1 regulates lung cancer cell growth, with the potential to become novel targets in the treatment of NSCLC.

\section{Materials and methods}

FIGNL1 immunohistochemical staining and clinical survival trace

Sample collection. Clinical samples were collected from patients with non-small cell lung cancer (NSCLC) at the Department of Pathology, the First Affiliated Hospital of Bengbu Medical College (Anhui, China) between May 2012 and October 2015, under the regulations of the Institutional Review Boards of the First Affiliated Hospital of Bengbu Medical College (approval no. BYYFY-2017.KY05). All patients provided written informed consent for clinical treatment, under the regulations of the Declaration of Helsinki. Cancerous and para-cancerous tissues $(\sim 5 \mathrm{~cm}$ around the cancerous tissues) were collected from 109 patients, all of whom were diagnosed with primary lung cancer; none of the patients had received chemotherapy, radiotherapy or targeted therapy before tissue collection.
Staining methods. The samples were sliced at a thickness of $0.1 \mathrm{~mm}$, followed by fixation with $4 \%$ paraformaldehyde at $4^{\circ} \mathrm{C}$ for $2 \mathrm{~h}$, and then coated with paraffin. The tissues were then subjected to standard dewaxing and rehydration. The sections were incubated in citric acid buffer ( $\mathrm{pH}$ 6.0) for $15 \mathrm{~min}$ for antigen retrieval, followed by incubation for $10 \mathrm{~min}$ with $3 \% \mathrm{H}_{2} \mathrm{O}_{2}$ solution to inactivate endogenous enzymatic activity. The sections were then blocked with $5 \%$ goat serum (Beyotime Institute of Biotechnology) at room temperature for $10 \mathrm{~min}$ then, incubated overnight with the primary anti-FIGNL1 antibody (dilution at 1:200; cat. no. ab185674; Abcam) at $4^{\circ} \mathrm{C}$. Subsequently, the sections were washed with PBS the next day and incubated with the Elivision ${ }^{\mathrm{TM}}$ plus Polyer HRP (mouse/rabbit) immunohistochemistry kit (pre-diluted; cat. no. KIT-9903; Maxim Biotech, Inc.) as the secondary antibody at $20^{\circ} \mathrm{C}$ for $30 \mathrm{~min}$. Next, the sections were stained with DAB staining fluid for $3 \mathrm{~min}$, followed by counterstaining with hematoxylin for $3 \mathrm{~min}$, both at room temperature. Lastly, the sections were treated with neutral balsam for permanent use. The stained sections were then observed and classified based on sex, age, tumor size, pathology type, nodal invasion conditions, and Tumor-Node-Metastasis stage, according to the 8th edition Union for International Cancer Control Lung Cancer Stage Classification (25). At least 5 fields of view were randomly selected in each section and counted at x400 magnification with an inverted light microscope (Shanghai Caikang Electronic Co., Ltd.).

Classification criteria. Positive FIGNL1 staining was defined as the appearance of clear brown or sepia color in the cytoplasm and positive intensity was calculated using the following equation: Positive stained cell count/the total cell count. Each section was scored using the following criteria: 0 , No positive staining $(<5 \%)$; 1 , weak positive staining $(5-25 \%)$; 2 , moderate positive staining (25-50\%); and 3, strong positive staining $(50 \%)$. A score $<1$ was indicative of low FIGNL1 expression, whereas a score $\geq 2$ was considered to indicate high FIGNL1 expression; para-carcinoma tissues were used as the negative control for the cancerous tissues. In addition, the ratio between the late stage (stage III) and early stage (stage I and II) was compared to determine the effect of FIGNL1 on lung cancer development. Furthermore, overall survival analysis (total duration of 81 months) of the 109 patients was performed (mean follow-up, 50.924 \pm 2.807 months) to assess the effect of FIGNL1 on patient survival.

Cell culture. The H460, H23, H1299 and A549 cell lines were obtained from China Centre for Type Culture Collection, and cultured with RPMI 1640 medium (Gibco; Thermo Fisher Scientific, Inc.), with $10 \%$ fetal bovine serum (Gibco; Thermo Fisher Scientific, Inc.) at $37^{\circ} \mathrm{C}$ in a humidified incubator (SANYO, Electric Co., Ltd.) with $5 \% \mathrm{CO}_{2}$. Cell passage was performed using PBS and a 2-min incubation with $0.25 \%$ trypsin (Gibco; Thermo Fisher Scientific, Inc.). Images of the transfected cells were captured using a fluorescent microscope (Olympus Corporation), while for the wound healing, invasion and Transwell assays, an inverted light microscope (Shanghai Caikang Electronic Co., Ltd.) was used. The cell lines were authenticated using a PCR-based method for single-locus analysis; strict sterilization conditions 
Table I. Sequences for the shRNAs.

\begin{tabular}{|c|c|}
\hline shRNA name & Sequence $\left(5^{\prime}-3^{\prime}\right)$ \\
\hline shRNA F & GATCCGTTCTCCGAACGTGTCACGTAATTCAAGAGATTACGTGACACGTTCGGAGAATTTTTTC \\
\hline shRNA R & AATTGAAAAAATTCTCCGAACGTGTCACGTAATCTCTTGAATTACGTGACACGTTCGGAGAACG \\
\hline shRNA1 F & GATCCGCTACCATAACACCGGATCAATTCAAGAGATTGATCCGGTGTTATGGTAGCTTTTTTG \\
\hline shRNA1 R & AАTTCAAAAAAGCTACCATAACACCGGATCAATCTCTTGAATTGATCCGGTGTTATGGTAGCG \\
\hline shRNA2 F & GATCCGCCGGAGAGCAATCGTTTGAAATTCAAGAGATTTCAAACGATTGCTCTCCGGTTTTTTG \\
\hline shRNA2 R & АATTCAAAAAACCGGAGAGCAATCGTTTGAAATCTCTTGAATTTCAAACGATTGCTCTCCGGCG \\
\hline shRNA3 F & GATCCGCCGTGCACAGATATTACGCATTTCAAGAGAATGCGTAATATCTGTGCACGGTTTTTTG \\
\hline shRNA3 R & AATTCAAAAAACCGTGCACAGATATTACGCATTCTCTTGAAATGCGTAATATCTGTGCACGGCG \\
\hline
\end{tabular}

sh, short hairpin; F, forward; R, reverse.

for cell culture were maintained and mycoplasma testing was routinely performed.

Recombinant vector construction and cell transfection. The interference vector, pHBLV-U6-MCS-CMV-ZsGreen-PGK -PURO (5 $\mu \mathrm{g}$; Hanbio Biotechnology Co., Ltd.) was linearized using double restriction digestion and BamHI and EcoRI (Thermo Fisher Scientific, Inc.), purified using a Gel-Spin DNA Extraction kit (Shanghai Generay Biotech Co., Ltd.) then, ligated with short hairpin (sh)RNAs, using T4 ligase (Fermentas; Thermo Fisher Scientific, Inc.). The susceptible cells, DH5 $\alpha$ (Tiangen Biotech Co., Ltd.) were transfected with the recombinant vectors, pSPAX2 (Hanbio Biotechnology Co., Ltd., $10 \mu \mathrm{g}$ ) and pMD2G (Hanbio Biotechnology Co., Ltd., $5 \mu \mathrm{g})$ and the interference vector linked with targeted shRNA $(10 \mu \mathrm{g})$, which were harvested using a Plasmid MaxPrep kit (Tiangen Biotech, China). All the vectors were then transfected together into 293T cells using the LipoFiter ${ }^{\mathrm{TM}}$ Transfection Reagent (Hanbio Biotechnology Co., Ltd.) according to the manufacturer's instructions, followed by enhanced green fluorescent protein fluorescence and puromycin screening of the pHBLV-U6-MCS-CMV-ZsGreen-PGK-PURO shuttle vector positive cells. High titers $\left(>10^{8}\right.$ transforming units $\left./ \mathrm{ml}\right)$ of the concentrated lentivirus solutions were harvested from the supernatant. The designed shRNAs (TsingKe Biological Technology) are presented in Table I. The shRNAs were diluted to $0.1 \mathrm{nmol}$ for the downstream reaction, and the transfected cells were passaged to at least 5 generations (transfected after $24 \mathrm{~h}$ of culturing), followed by the subsequent experiments. The H1299 cells were divided into 4 groups: Cells transfected with positive control (shCtrl), shRNA1, shRNA2 and shRNA3, respectively, while the A549 cells were transfected with either shCtrl or shRNA1. The cell lines, in which no transfection was performed are defined as the negative control group.

Assessment of cell proliferation. Cell proliferation was investigated using a Cell Counting Kit-8 (CCK-8) assay (Xi'an Baiying Biotechnology Co., Ltd.) according to the manufacturer's instructions. Cells were seeded into 96-well plates, at a density of 1,000 cells per well $(100 \mu \mathrm{l})$, and the absorbance was measured at $450 \mathrm{~nm}$. Then, $10 \mu \mathrm{l}$ CCK- 8 reagent was added to each well for $2 \mathrm{~h}$ each day, then the absorbance of each well was measured at $0,24,48,72$, and $96 \mathrm{~h}$. The absorbance indicated cell counts obtained within a day, and the ratio between subsequent and primary absorbance was considered as the fold proliferation rate.

Reverse transcription-quantitative PCR (RT-qPCR). Total RNA was extracted from the cells using a RNA extraction kit (Wuhan Servicebio Technology Co., Ltd.), and the cDNA was generated using a RevertAid First Strand cDNA Synthesis kit (Thermo Fisher Scientific, Inc.), according to the manufacturer's guidelines. The total RNA and cDNA were quantified and confirmed using a NanoDrop ${ }^{\mathrm{TM}} 2000$ spectrophotometer (Thermo Fisher Scientific, Inc.) and agarose gel electrophoresis. The FastStart Universal SYBR Green master mix (Roche Diagnostics) was used for qPCR on a thermocycler (model 7300; Applied Biosystems; Thermo Fisher Scientific, Inc.). The primers in Table II were synthesized by Tsingke Biotechnology Corporation. Each well included $0.5 \mu \mathrm{l}$ both forward and reverse primers, $2 \mu \mathrm{l}$ cDNA (50 ng/ $\mu \mathrm{l}), 10 \mu \mathrm{l}$ $2 \mathrm{X}$ SYBR Green mix, and $7 \mu$ l double distilled water, in a total volume of $20 \mu \mathrm{l}$. For the RT-qPCR each sample had 3 replicates, and each group of samples contained three biological repeats. To determine the specific PCR conditions (annealing temperature, a standard PCR was performed using the primers. The following thermocycling conditions were used: Initial denaturation at $95^{\circ} \mathrm{C}$ for $5 \mathrm{~min}$, followed by 40 cycles at $95^{\circ} \mathrm{C}$ for $10 \mathrm{sec}$, annealing and extension at $58^{\circ} \mathrm{C}$ for $60 \mathrm{sec}$, and the final melting curve analysis was performed using the instrument's default settings. The $\mathrm{Cq}$ values were exported and normalized to the housekeeping gene, GAPDH as described by Livak and Schmittgen (26).

FIGNL1 overexpression vector construction and cell transfection. The human FIGNL1 CDS was obtained from the cDNAs extracted as aforementioned by cloning using the primers, H-FIGNL1 (CDS)-forward and reverse, as shown in Table II. Subsequently, the exogenous fragment was ligated into the pLenO-GTP-C-3XFlag vector (Hanbio Biotechnology Co., Ltd.), using the restriction enzymes EcoRI and BamHI, and T4 ligase (both from Takara Bio, Inc.) (Fig. S1). The recombinant vector was successfully transformed into DH5 $\alpha$ cells and the plasmids were selected from endotoxin screening. DNA sequencing was performed to confirm the absence 
Table II. Primers for reverse transcription-quantitative PCR.

\begin{tabular}{llc}
\hline Name & \multicolumn{1}{c}{ Sequence $\left(5^{\prime}-3^{\prime}\right)$} & Tm $\left({ }^{\circ} \mathrm{C}\right)$ \\
\hline H-FIGNL1-S & GGAGCAACAAATCGGCCACAA & 60 \\
H-FIGNL1-A & ATGTCTGCTCCTGAAAACGCATC & 60 \\
H-FIGNL1 (CDS)-S & TAGAGCTAGCGAATTCATGCAGACCTCCAGCTCTAG & 60 \\
H-FIGNL1 (CDS)-A & CTTTGTAGTCGGATCCCTTTCCACAACCAAAAGTTTTGTTC & 60 \\
H-GAPDH-S & TGACTTCAACAGCGACACCCA & 60 \\
H-GAPDH-A & CACCCTGTTGCTGTAGCCAAA & 60 \\
PCNA-S & ACACTAAGGGCCGAAGATAACG & 60 \\
PCNA-A & ACAGCATCTCCAATATGGCTGA & 60 \\
MCM2-S & ATGATCGAGAGCATCGAGAACC & 60 \\
MCM2-A & GCCAAGTCCTCATAGTTCACCA & 60 \\
MCM4-S & GACGTAGAGGCGAGGATTCC & 60 \\
MCM4-A & GCTGGGAGTGCCGTATGTC & 60 \\
SKP2-S & ATGCCCCAATCTTGTCCATCT & 60 \\
SKP2-A & CACCGACTGAGTGATAGGTGT & 60 \\
\hline
\end{tabular}

S, sense; A, antisense; FIGNL1, fidgetin like 1.

of any mutation in the complete FIGNL1 CDS region, then the recombinant vector $(5 \mu \mathrm{g})$ was transfected into the A549 and H1299 cell lines, according to the lentiviral transfection guidelines according to the manufacturer's protocol. Following FIGNL1 overexpression, cell proliferation was determined using a CCK-8 assay, as aforementioned.

Western blot analysis. Total protein was extracted using RIPA lysis buffer, containing $1 \mathrm{mg} / \mathrm{ml}$ phenylmethylsulfonyl fluoride (Beyotime Institute of Biotechnology) on ice for $30 \mathrm{~min}$. The protein concentration was calculated using the bicinchoninc acid protein assay kit (Beyotime Institute of Biotechnology), according to the manufacturer's protocols, then the samples were denatured for $10 \mathrm{~min}$ at $95^{\circ} \mathrm{C}$. The protein samples $(60 \mu \mathrm{g}$ in each lane) and prestained protein marker (Thermo Fisher Scientific, Inc.) were separated using SDS-PAGE (5\% upper and 10\% lower) (Beyotime Insitute of Biotechnology), transferred to nitrocellulose membranes, which were subsequently blocked with 5\% skimmed milk in PBS-Tween-20 buffer at the room temperature for $1 \mathrm{~h}$, and incubated overnight at $4^{\circ} \mathrm{C}$ with the primary antibodies (rabbit FIGNL1; cat. no. 17604-1-AP; dilution at 1:1,000; ProteinTech Group, Inc. or mouse GAPDH, cat. no. ab181602; dilution at 1:10,000; Abcam). Then, the membranes were incubated with the secondary antibody (goat anti-mouse $\operatorname{IgG}$, cat. no. 31160; dilution at 1:5,000 or goat anti-rabbit IgG; cat. no. 31210; dilution at 1:5,000) (both from Thermo Fisher Scientific, Inc.) at room temperature for $1 \mathrm{~h}$, and the proteins were detected using an enhanced chemiluminescence-plus kit (Thermo Fisher Scientific, Inc.). Images were obtained using a ChemiDoc $\mathrm{XR}^{+}$detection system (Bio-Rad Laboratories, Inc.). The gray-scale data was normalized to GAPDH. The following primary antibodies were used: Rabbit anti-FIGNL1 and mouse GAPDH (both ProteinTech Group, Inc.). The following secondary antibodies were used: Goat anti-mouse IgG and goat anti-rabbit IgG (both ProteinTech Group, Inc.).
Cell cycle and apoptosis analysis using flow cytometry. The H1299 and A549 cell lines were harvested with trypsin (under $37^{\circ} \mathrm{C}$ ) and centrifugation at $300 \mathrm{x} \mathrm{g}$ (at room temperature for $5 \mathrm{~min}$ ), and stained with either a cell cycle detection kit (containing PI; Sigma-Aldrich; Merck KGaA), with RNase A (Fermentas; Thermo Fisher Scientific, Inc.) or with Annexin V-APC for cell apoptosis detection (AAT Bioquest Inc.), according to the manufacturer's instructions. For cell cycle detection, the cells were stained at room temperature for $20 \mathrm{~min}$, while for apoptosis analysis, the cells were incubated at room temperature for $60 \mathrm{~min}$. Both experiments required the avoidance of light. A Guava easyCyte HT flow cytometer (EMD Millipore) was used to perform the experiments and the FlowJo software (v10.0.7; FlowJo, LLC) was used to analyze the cell cycle and apoptosis data. Each group of samples included three biological repeats for data analysis.

Clonality assay. A total of 1,000 cells were seeded into each well of a 6-well culture plate (Corning, Inc.). Cells were cultured for 14 days or until the cell count of a single clone was $>50$. The cells were washed with PBS and images were captured using an inverted microscope prior to staining with crystal violet (Sangon Biotech Co., Ltd.) for 10-20 min at the room temperature, then washed with sterilized double distilled water. Images were captured again using an inverted light microscope at $\mathrm{x} 400$ magnification. The cell count of a single clone indicated clonality.

Wound healing and cell invasion assays. A total of $1.5 \times 10^{5}$ cells (H1299 and A549) were seeded into each well of a 12-well culture plate and medium was replaced the following day, containing a low concentration of serum $(0.5 \% \mathrm{FBS}$; Gibco; Thermo Fisher Scientific Inc.). The wound was created using a $10 \mu \mathrm{l}$ pipette tip in each well after the cell density reached $100 \%$ confluency, and images were obtained using an 
inverted light microscope at $\mathrm{x} 400$ magnification, at the start of the assay and following $24 \mathrm{~h}$ of culture. The migration ratio was calculated based on the images using ImageJ software (version 1.52a; National Institutes of Health.).

Cell Transwell (cat. no. 3422) and invasion assays (cat. no. 354480) (both from Corning Inc.) were performed according to the manufacturer's instructions. During the Transwell assay, cells were suspended at the concentration of $1 \times 10^{6}$ cells $/ \mathrm{ml}$ with serum-free medium, before seeding into the upper chambers (100 $\mu \mathrm{l}$ in each chamber), while the lower chambers contained medium with $30 \%$ FBS. After culturing at $37^{\circ} \mathrm{C}$ in a humidified incubator with $5 \% \mathrm{CO}_{2}$ for $48 \mathrm{~h}$, the cells that have migrated into the lower chambers were stained with crystal violet (at room temperature for $3 \mathrm{~min}$ ) and observed using an inverted light microscope. The invasion assay was conducted using the same method; however, Corning $^{\circledR}$ BioCoat $^{\mathrm{TM}}$ Matrigel $^{\circledR}$ invasion chambers were used (Corning, Inc.), and the medium in the lower chambers contained medium with 20\% FBS $(600 \mu \mathrm{l})$.

Cell line derived tumor xenograft experiments. A total of 14,6 -week old male BALB/c nude mice (weighing $16.58 \pm 0.45 \mathrm{~g}$ ) were used and divided into the control group (7 mice) and the experimental group ( 7 mice) for the tumor xenograft experiments. The H1299 cell line was transfected with shCtrl or shFIGNL1 and resuspended with PBS, at a density of $2 \times 10^{7}$ cells $/ \mathrm{ml}$. A total of $2 \times 10^{6}$ cells $(100 \mu \mathrm{l})$ were injected into the armpits of the 8 -week old male BALB/c nude mice on day 1 . The mice in the control group weighed $19.82 \pm 0.50 \mathrm{~g}$, while the mice in the experimental group weighed $19.57 \pm 0.34 \mathrm{~g}$. The weight and volume of the tumors were measured every 2 days, using a Lumina Series III imaging system (PerkinElmer, Inc.) starting on day 7. The tumor volume was calculated using the following equation: Volume $\left(\mathrm{mm}^{3}\right)=(\pi / 6) \mathrm{x}$ length $\mathrm{x}$ width $\mathrm{x}$ height.

The mice were purchased from the Shanghai SLAC Laboratory Animal Co. Ltd., and all experimental procedures involving animals were under the regulations of the Guide for the Care and Use of Laboratory Animals and the Animal Welfare Act with supervision from the Bengbu Medical College Experimental Animal Experimental Ethics Committee (approval no. 2017-091). The mice were all raised in a certified specific pathogen-free environment [with ad libitum access to food and water under controlled temperature $\left(25^{\circ} \mathrm{C}\right)$, humidity $(50-80 \%)$, and a 12 -h light cycle]. Animals were housed 3-5 mice per cage and acclimatized for at least 7 days prior to the start of the study. The mice were all under good health conditions, and no mice died following the injection of the cancer cells. The behaviors including normal activities (playing, determining dominance, sleeping and grooming), alertness (fighting, isolation from the group, barbering, vocalization, circling, lethargy and rearing up or sniffing), as well as pathophysical signs (tumor growth, respiration rate, and weight loss) were all monitored. The animals were sacrificed by cervical translocation at the end of the experiment and death was verified by non-pupillary response to light, lack of spontaneous breathing and cardiac arrest for at least $5 \mathrm{~min}$, and the tumor tissues were harvested for subsequent volume and weight measurement.
cDNA microarray. Total cell RNA was extracted using TRIzol $^{\circledR}$ (Invitrogen; Thermo Fisher Scientific, Inc.) then, the RNA sample were sent to Aksomics Inc., for them to perform cDNA microarray analysis, using the Agilent ${ }^{\circledR}$ Human 4x 44K gene expression microarrays v2 (Agilent Technologies Inc.). Differential gene expression profiles were analyzed between H1299 control and FIGNL1 knockdown cells, using biocomputational techniques and further analyzed using The Database for Annotation, Visualization and Integrated Discovery online analysis tool, with the Gene Ontology (GO) $(27,28)$ and Kyoto Encyclopedia of Genes and Genomes (KEGG) databases (https://genome.jp/kegg/pathway.html). $\mathrm{P}<0.05$ was considered to indicate a statistically significant difference for GO terms and KEGG pathways.

Statistical analysis. Data are presented as the mean \pm standard deviation. All experiments were repeated at least three times. Between-group differences were analyzed using the Student's unpaired t-test (parametric) or one-way ANOVA Sidak's post hoc test. $\mathrm{P}<0.05$ were considered to indicate a statistically significant difference. Statistical analyses were performed using the SPSS statistics software (v25.0; IBM Corp.) and the graphs were generated using GraphPad Prism v8.0 (GraphPad Software, Inc.).

\section{Results}

During our previous research (Figs. S2 and S3) (5), FIGNL1 was found to decrease cell proliferation by 2.90 -fold compared with that in the negative control using high content screening method. Thus, to identify the potential function of FIGNL1, RNA interference experiment was performed to knockdown the expression level of FIGNL1. A total of 3 shRNAs were designed and transfected into the lung cancer cell lines. FIGNL1 knockdown led to decreased proliferation of lung cancer cells and induced alterations in cell cycle, while increasing the ratio of apoptosis and reduced the migratory and invasive abilities of the lung cancer cells. The common NSCLC cell lines (A549 and H1299) were used in the present study.

Survival curve and clinical immunohistochemical analysis for FIGNL1. Immunohistochemical staining was performed from 109 cancerous and para-carcinoma lung tissue samples collected from patients with NSCLC, to determine the FIGNL1 expression level in cancerous lung tissues. Analysis of the results revealed that 93 patients were classified into the low FIGNL1 expression group, while 16 patients were classified into the high FIGNL1 expression group (Fig. 1A-E and Table III). The mean follow-up period was $50.924 \pm 2.807$ months (overall follow-up was 81 months). Survival analysis revealed no significant difference of FIGNL1 expression on patient survival $(\mathrm{P}=0.2023)$. The distribution of FIGNL1 expression in the cancerous and para-carcinoma tissues is shown in Fig. 2A. A total of 83 cancer tissue specimens $(76.1 \%)$ had positive FIGNL1 expression, while only 2 para-carcinoma tissues $(1.8 \%)$ had positive expression. To determine the effect of FIGNL1 on survival outcomes, Kaplan-Meier curves were generated (Fig. 2B). The predicted average and median survival time are presented in Table IV. In addition, it was found that the later TNM stage of lung cancer 
Table III. Data summary of the survival records.

\begin{tabular}{lccccccr}
\hline $\begin{array}{l}\text { Expression } \\
\text { level }\end{array}$ & $\begin{array}{c}\text { Number of } \\
\text { Patients }\end{array}$ & $\begin{array}{c}\text { Censored } \\
\text { Subjects }\end{array}$ & $\begin{array}{c}\text { Survival } \\
\text { percentage }\end{array}$ & $\begin{array}{c}\text { Death } \\
\text { events }\end{array}$ & $\chi^{2}$ & $\begin{array}{c}\text { Degree of } \\
\text { freedom }\end{array}$ & P-value \\
\hline Low & 93 & 47 & 50.5 & 46 & 1.626 & 1 & 0.2023 \\
High & 16 & 6 & 37.5 & 10 & & & \\
\hline
\end{tabular}
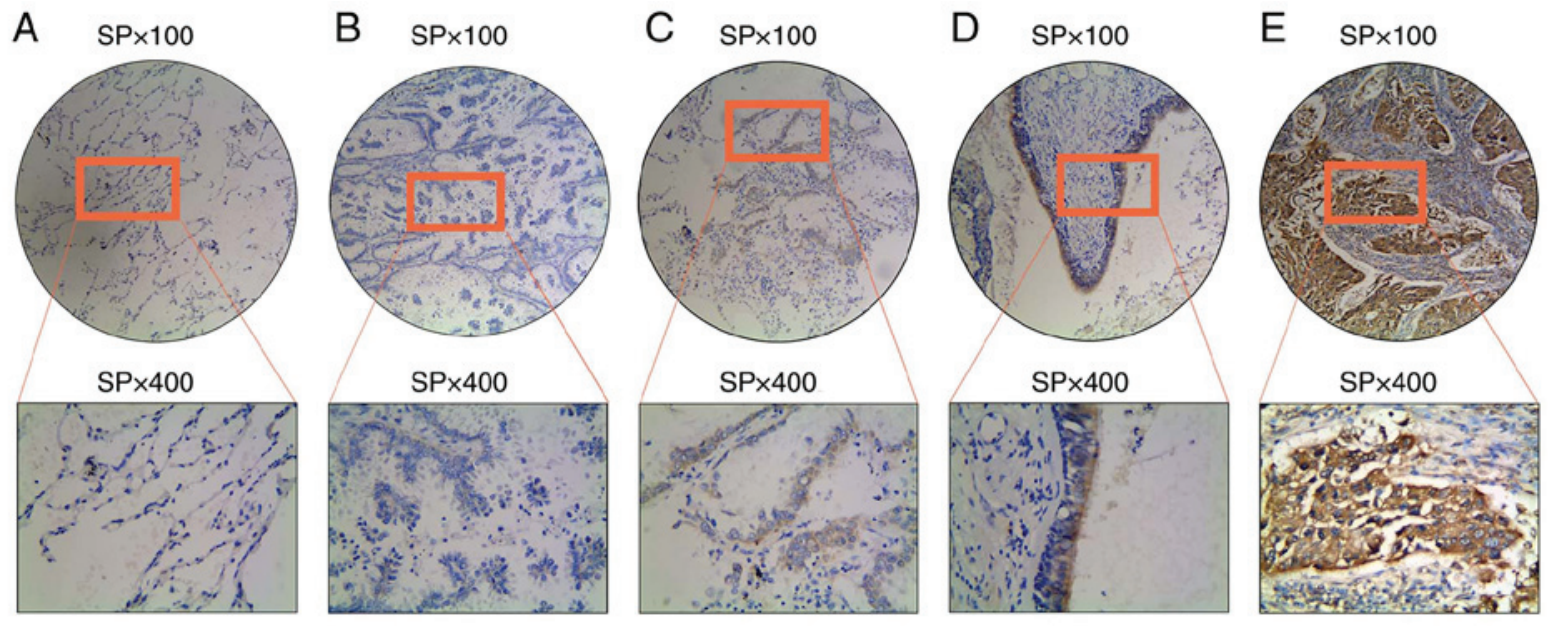

Figure 1. Representative immunohistochemical images showing FIGNL1 expression in cancerous and para-carcinoma tissues. (A) FIGNL1 negative staining in para-carcinoma tissues (score, 0). (B) Negative FIGNL1 staining in carcinoma tissues (score, 0). (C) Weak positive staining for FIGNL1 in cancerous tissues (score, 1). (D) Moderate positive staining for FIGNL1 in cancerous tissues (score, 2). (E) Strong positive staining for FIGNL1 in cancerous tissues (score, 3). FIGNL1, fidgetin-like 1. SP, streptavidin-peroxidase.
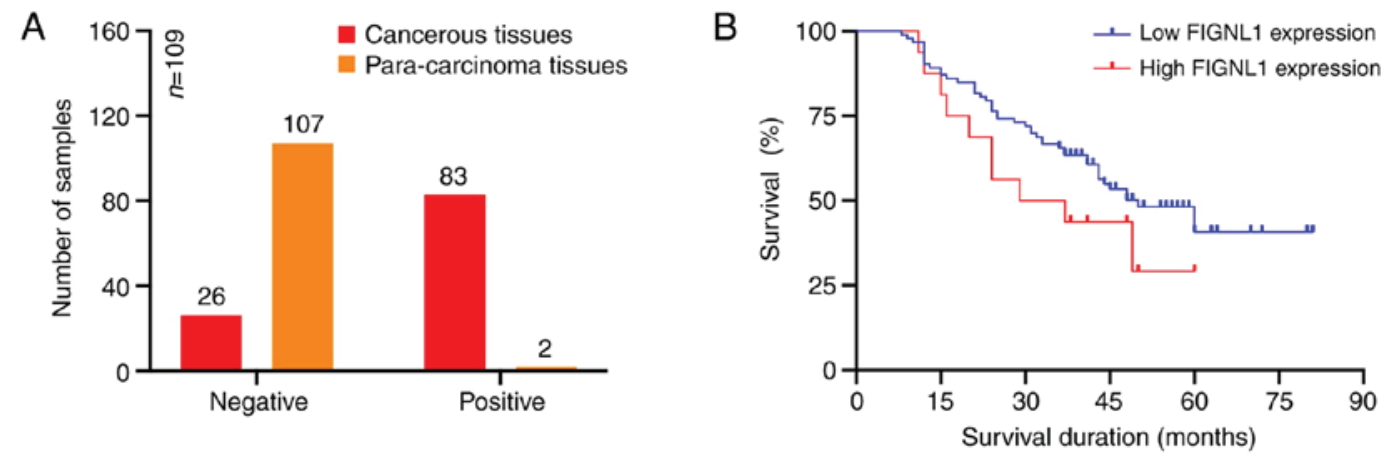

Figure 2. Effects of FIGNL1 protein expression level on patient survival. (A) FIGNL1 protein expression level in cancerous and para-carcinoma tissues using immunohistochemical staining. A higher number of cancerous tissues showed positive FIGNL1 staining. (B) Survival curves of patients with lung cancer and low or high protein expression level of FIGNL1. FIGNL1, fidgetin-like 1.

diagnosis, the patients had higher FIGNL1 expression levels; however, FIGML1 expression was not associated with sex, age, tumor size or pathological type (adenocarcinoma or squamous carcinoma), but it was significantly associated with nodal invasion and TNM stage (Table V).

Construction of RNA interference vector. To facilitate a comprehensive characterization of FIGNL1 expression in lung cancer cells, the cell lines with higher expression of FIGNL1, were used to construct a knockdown cell line. As shown in Fig. 3, FIGNL1 mRNA and protein expression levels were at relatively high levels, and their expression levels were also stable in the H1299 and A549 cell lines; therefore, these were used for further experimentation (RNA interference) and more suitable for the xenograft experiment. During the RNA interference experiments, a total of 3 shRNAs were designed and successfully ligated into the interference vector, pHBLVU6-MCS-CMV-ZsGreen-PGK-PURO, which was then transfected into 293T together with pSPAX2 and pMD2G. DNA sequencing results proved the successful assembly of the recombinant shuttle vector (Fig. S4).

Lentiviral transfection. The recombinant vectors were harvested and then transfected into 293T cells to produce virions to infect the A549 and H1299 cell lines. As shown in Table VI, viral titer was determined in the H1299 and 
Table IV. Predicted mean and median survival duration from the survival curve of the patients.

\begin{tabular}{lcccc}
\hline Group & Mean survival \pm SD, months & 95\% CI & Median survival \pm SD, months & 95\% CI \\
\hline Low & $52.219 \pm 3.014$ & $46.312-58.126$ & $50.000 \pm 6.226$ & $37.796-62.204$ \\
High & $36.396 \pm 4.828$ & $26.933-45.858$ & $29.000 \pm 13.000$ & $3.520-54.480$ \\
Total number of patients & $50.924 \pm 2.807$ & $45.422-56.425$ & $48.000 \pm 5.155$ & $37.896-58.104$ \\
\hline
\end{tabular}

CI, confidence interval.

Table V.Association of the clinicopathological parameters between the low and high expression FIGNL1 groups in patients with lung cancer.

FIGNL1 expression level

\begin{tabular}{|c|c|c|c|c|}
\hline Clinicopathological parameters & Number of patients & Low & High & P-value \\
\hline \multicolumn{5}{|l|}{ Sex } \\
\hline Male & 77 & 66 & 11 & 0.857 \\
\hline Female & 32 & 27 & 5 & \\
\hline \multicolumn{5}{|l|}{ Age, years } \\
\hline$\geq 60$ & 52 & 41 & 11 & 0.068 \\
\hline$<60$ & 57 & 52 & 5 & \\
\hline \multicolumn{5}{|l|}{ Tumor size, $\mathrm{cm}$} \\
\hline$>3.0$ & 47 & 39 & 8 & 0.547 \\
\hline$\leq 3.0$ & 62 & 54 & 8 & \\
\hline \multicolumn{5}{|l|}{ Pathological type } \\
\hline Adenocarcinoma & 67 & 56 & 11 & 0.517 \\
\hline Squamous Carcinoma & 42 & 37 & 5 & \\
\hline \multicolumn{5}{|l|}{ Nodal Invasion } \\
\hline $\mathrm{N}_{0}$ & 66 & 60 & 6 & 0.036 \\
\hline $\mathrm{N}_{1} / \mathrm{N}_{2} / \mathrm{N}_{3}$ & 42 & 32 & 10 & \\
\hline \multicolumn{5}{|l|}{ TNM stage } \\
\hline I+IIA & 77 & 70 & 7 & 0.011 \\
\hline IIB+III & 32 & 23 & 9 & \\
\hline
\end{tabular}

FIGNL1, fidgetin like 1 .

A

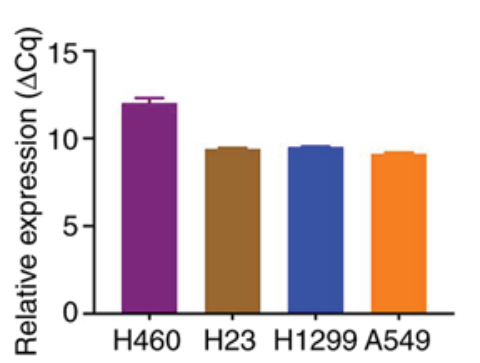

B
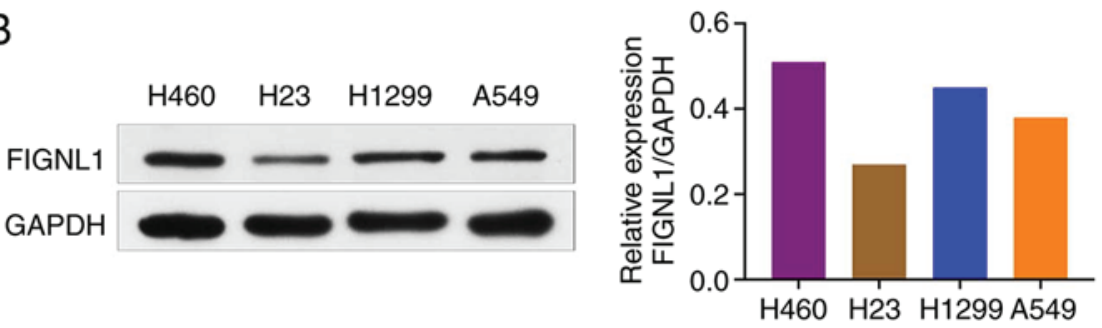

Figure 3. FIGNL1 protein and mRNA expression level in H460, H23, H1299 and A549 lung cancer cells determined using (A) reverse transcription-quantitative PCR and (B) western blot analysis. FIGNL1, fidgetin-like 1.

A549 cell lines prior to infection. The H1299 and A549 cell lines were then infected with lentivirus produced from 293T cells. The plasmid had the capability to express the GFP protein, which was used to evaluate the transfection efficiency. When cell density observed under the fluorescent field reached $70 \%$ (Fig. S5), the cells were collected for puromycin screening 
Table VI. Viral titer evaluation in transfecting the A549 and H1299 cell lines.

\begin{tabular}{lcccc}
\hline shRNA & Viral titer in A549, TU/ml & Infection volume, $\mu 1$ & Viral titer in H1299, TU/m & Infection volume, $\mu 1$ \\
\hline shCtrl & $2 \times 10^{8}$ & 20 & $2 \times 10^{8}$ & 2 \\
shRNA1 & $2 \times 10^{8}$ & 20 & $2 \times 10^{8}$ & 2 \\
shRNA2 & $2 \times 10^{8}$ & 20 & $2 \times 10^{8}$ & 2 \\
shRNA3 & $2 \times 10^{8}$ & 20 & $2 \times 10^{8}$ & 2 \\
\hline
\end{tabular}

si, short hairpin; Ctrl, control.
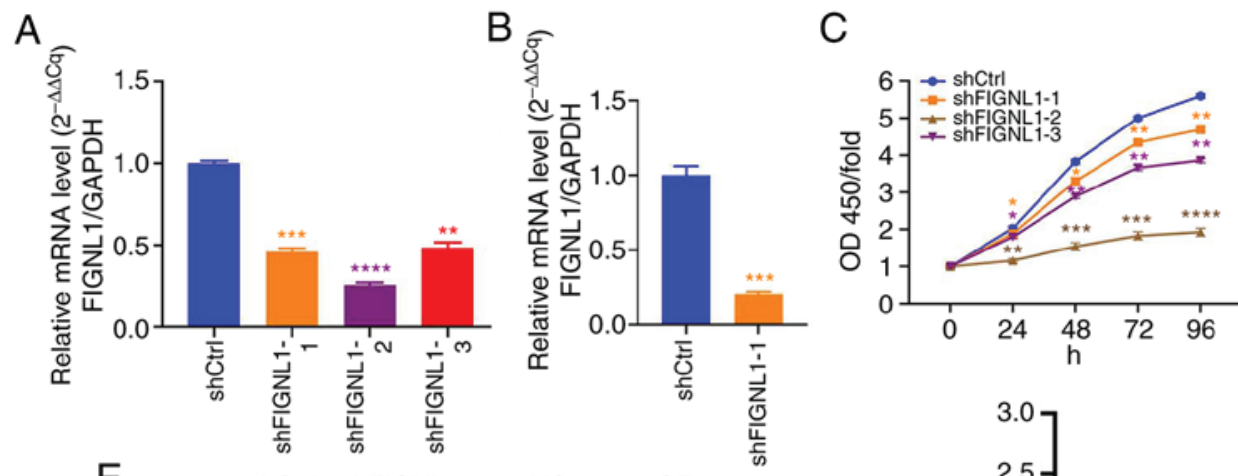

$\mathrm{D}$
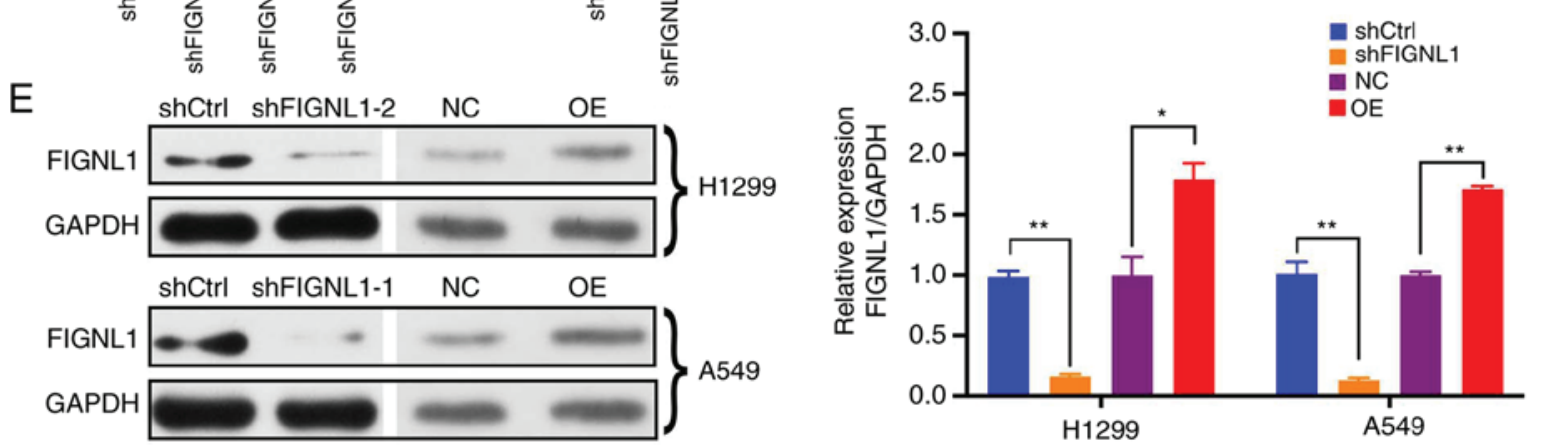

$\mathrm{F}$

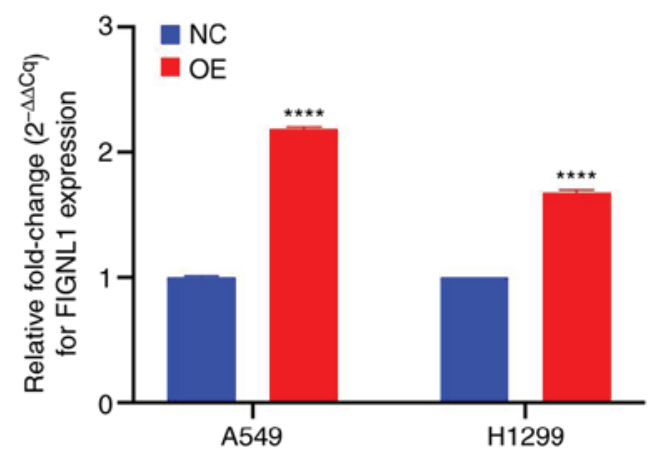

G

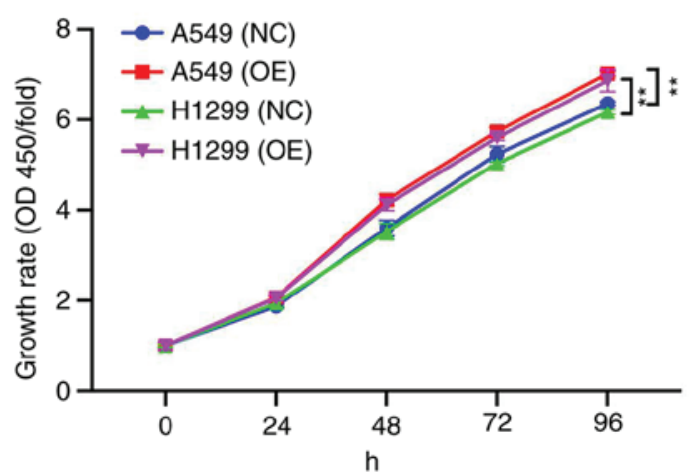

Figure 4. Examination of FIGNL1 protein and mRNA expression level and its effects on cell growth rate. (A) shFIGNL1-2 decreased the mRNA expression level the most, among the three shRNAs in H1299 cell line. (B) shFIGNL1-1 led to a significant decrease in mRNA expression level in A549 cells. (C) The three shRNAs inhibited growth at different levels; shFIGNL1-2 had the strongest ability to suppress cell growth in H1299 cell line. (D) Compared with that in the shCtrl group, shFIGNL1-1 could significantly reduce cell growth in the A549 cell line. (E) FIGNL1 protein expression levels following knockdown and overexpression in the H1299 and A549 cell lines. (F) FIGNL1 mRNA expression level was significantly increased following transfection with the overexpression vector in both cell lines. (G) Cell growth was significantly increased following overexpression of FIGNL1. ${ }^{*} \mathrm{P}<0.05,{ }^{{ }^{* *}} \mathrm{P}<0.01,{ }^{* * * *} \mathrm{P}<0.001,{ }^{* * * * *} \mathrm{P}<0.0001$. n=3. FIGNL1 knockdown using shFIGNL1-2 in H1299 cells and shFIGNL1-1 in A549 cells. sh, short hairpin; Ctrl, control; OD, optical density; NC, negative control; OE, overexpression; FIGNL1, fidgetin-like 1.

for $48 \mathrm{~h}$ until the cell density reached $70-80 \%$ confluence to perform downstream experiments.

FIGNL1 knockdown reduces cell proliferation and increases apoptosis. The results of RT-q PCR (Fig. 4A and B) and western blot analysis (Fig. 4E) revealed that the various shRNAs decreased FIGNL1 expression in the H1299 and A549 cell lines. For subsequent experiments, shFIGNL1-2 was selected in the H1299 cell line and shFIGNL1-1 for use in A549. Since shFIGNL1-2 induced the highest mRNA 

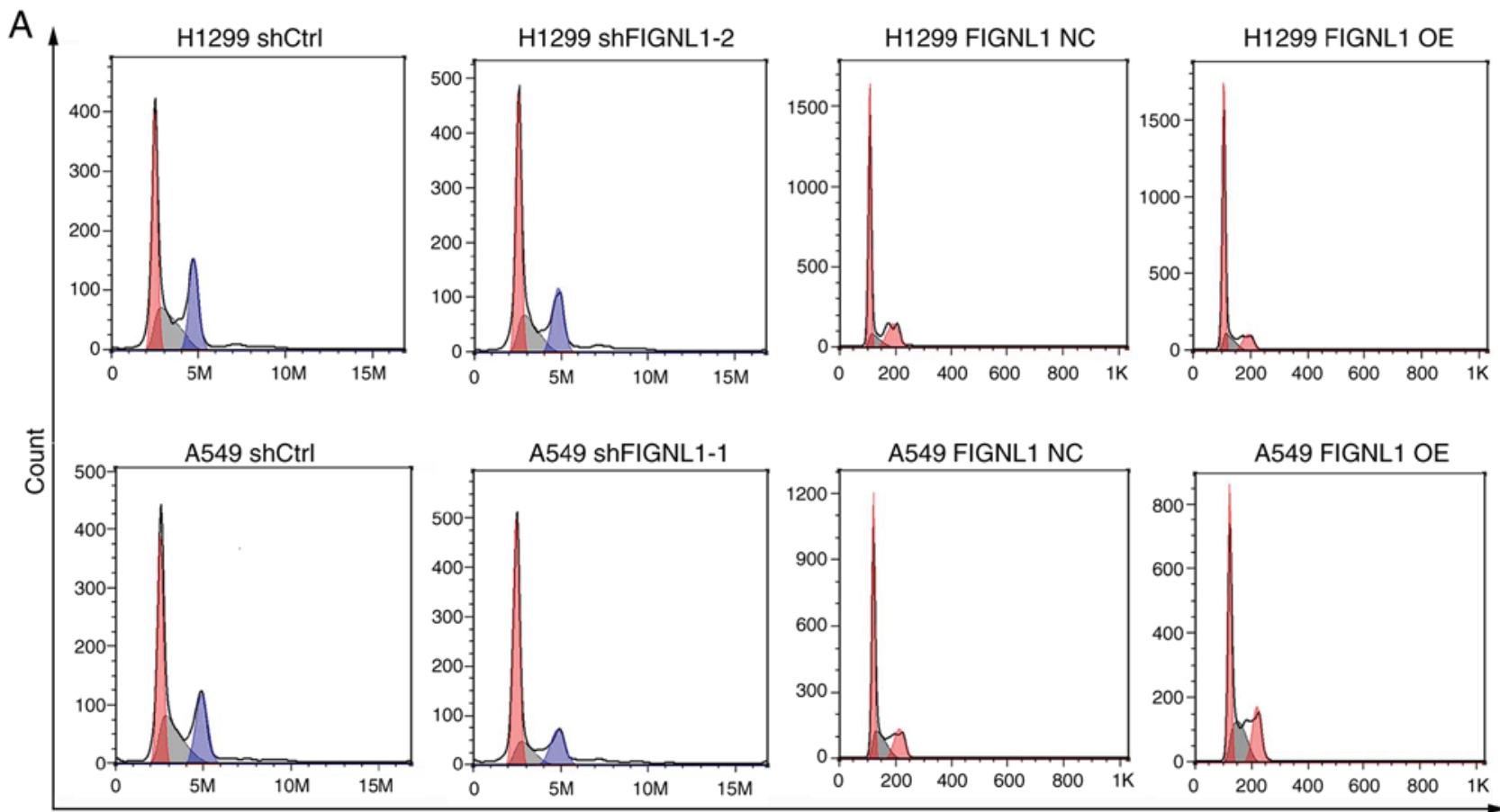

B

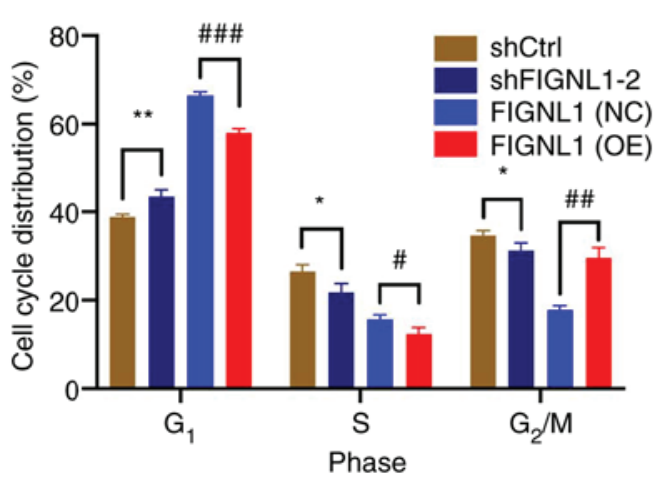

C

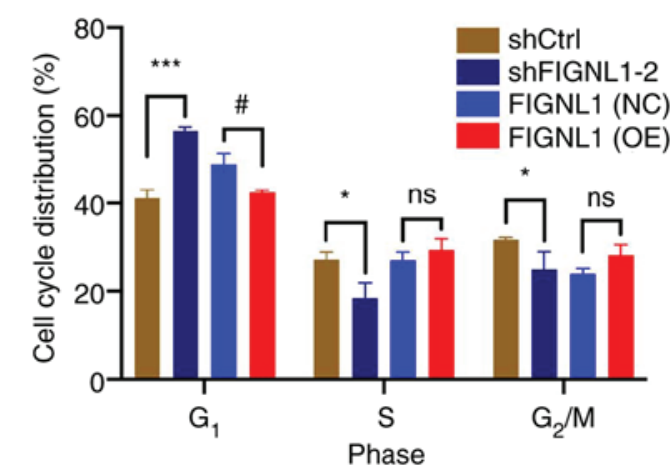

Figure 5. Effects of FIGNL1 knockdown and overexpression on cell cycle. (A) Flow cytometry plots showing the changes in the cell cycle shift in the H1299 and A549 cell lines following knockdown or overexpression of FIGNL1. In (B) H1299 and (C) A549 cell lines, FIGNL1 knockdown induced arrested cells in $\mathrm{G}_{1}$ stage and shortened $\mathrm{S}$ and $\mathrm{G}_{2} / \mathrm{M}$ phases. However, FIGNL1 overexpression had the opposite effect, with shortened $\mathrm{G}_{1}$ phase. ${ }^{*}, \# \mathrm{P}<0.05$, ${ }^{* *, \# \#} \mathrm{P}<0.01$,

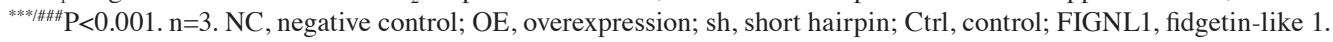

expression reduction by $74.3 \%$ among the three shRNAs in H1299 cells, and shFIGNL1-1 led to a 79\% decrease in mRNA expression level in A549 cells, these two shRNAs were used for the following experiments. The involvement of FIGNL1 in the regulation of cell proliferation was investigated using a CCK-8 assay, for 96 h. As shown in Fig. 4C and D, FIGNL1 knockdown induced a sharp decrease in cell growth rate compared with the control group. The effect of FIGNL1 overexpression was also investigated using an overexpressing vector and the results showed that the recombinant pLenO-GTP-C-3XFlag vector significantly increased the expression level of FIGNL1 in cells (Fig. 4E). In addition, cell proliferation was also significantly increased from FIGNL1 overexpression in both the H1299 and A549 cell lines (Fig. 4G).

Since altered cell proliferation and apoptosis may attenuate cell growth, flow cytometry assays were performed to investigate the effect of FIGNL1 knockdown and overexpression on cell growth. Cell cycle progression was analyzed between the control groups and the cells with knockdown or overexpression of FIGNL1. As shown in Fig. 5, FIGNL1 knockdown significantly increase in $G_{1}$ phase arrest $(P<0.05)$, as well as a significantly decreasing the cells at $S$ phase in both cells $(\mathrm{P}<0.05)$ compared with the shCtrl group. However, in the overexpression groups, increased FIGNL1 expression resulted in significantly reduced $\mathrm{G}_{1}$ phase arrest in both $\mathrm{H} 1299$ and A549 cells, along with non-significant changes in the $\mathrm{S}$ phase. In addition, lower FIGNL1 expression significantly increased cell apoptosis, while increased FIGNL1 expression significantly decreased the percentage of apoptotic cells $(\mathrm{P}<0.05$, Fig. 6). These results indicated that FIGNL1 plays an important role in cell proliferation and apoptosis, and that both factors might be responsible for attenuated cell growth rate. Detailed statistics for cell cycle and apoptosis distribution are presented in Tables VII-IX.

Effects of FIGNL1 on cell behavior. Following confirmation of the hypothesis that FIGNL1 could influence both cell proliferation and apoptosis, a further set of experiments were 

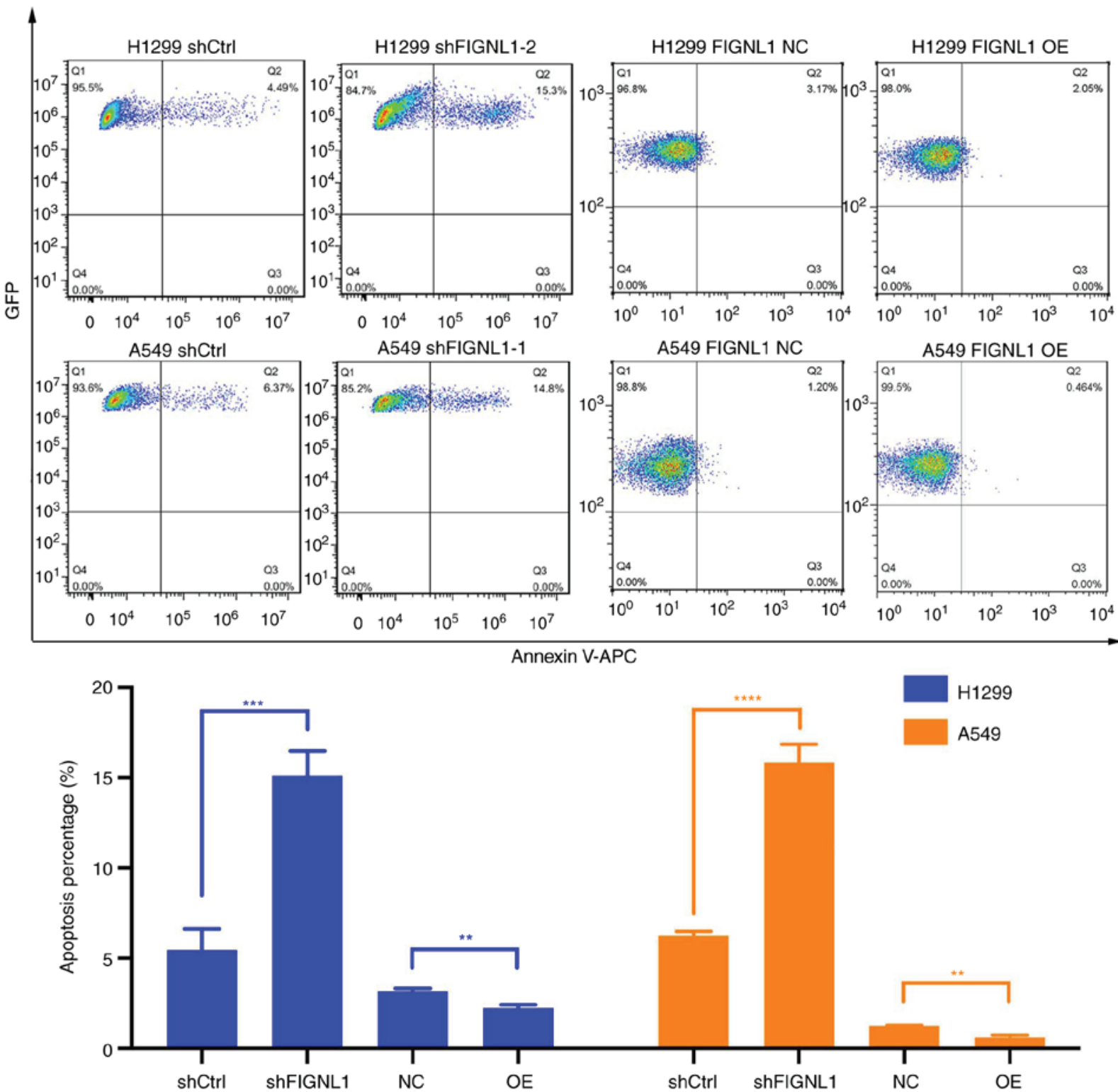

Figure 6. Effect of FIGNL1 knockdown and overexpression on cell apoptosis. Increased apoptotic rates were detected in both H1299 and A549 cells transfected with shFIGNL1, while cells with overexpression of FIGNL1 showed inhibition of apoptosis. ${ }^{* * *} \mathrm{P}<0.01,{ }^{, * * *} \mathrm{P}<0.001$ and ${ }^{* * * * *} \mathrm{P}<0.0001$. n $=3$. FIGNL1 knockdown using shFIGNL1-2 in H1299 cells and shFIGNL1-1 in A549 cells. NC, negative control; OE, overexpression; sh, short hairpin; Ctrl, control; FIGNL1, fidgetin-like 1.

performed for a more precise functional characterization of FIGNL1. First, clone formation assay was performed between the shRNA groups and overexpression groups in the H1299 and A549 cell lines (Fig. 7). The results showed a significant decrease in clonality in both the A549 and H1299 cell lines owing to the knockdown of FIGNL1 $(\mathrm{P}<0.05)$. However, overexpression of FIGNL1 showed no significant difference in colony formation. Furthermore, a wound healing assay was used to determine the migratory ability of both of the cell lines. Compared with that in the control group, both the cell lines, that had been transfected with shFIGNL1 showed a reduced migration ability, while the overexpression group exhibited significantly increased migratory ability to heal the wound $(\mathrm{P}<0.05$; Figs. 8 and 9). Consistent results were obtained from the Transwell and Matrigel assays (Fig. 10). Both cell lines transfected with shFIGNL1 (shFIGNL1-1 in A549 cells and shFIGNL1-2 in H1299 cells) exhibited a significant reduction in invasive growth, while the opposite results were observed following overexpression of FIGNL1 $(\mathrm{P}<0.05)$.

These findings suggested that FIGNL1 could be required for the maintenance of normal cell division and migration abilities, which are important for tumor formation and development in vivo. Functional disturbance of FIGNL1 may result in abnormal activity of lung cancer cells as indicated in vitro.

Effect of FIGNL1 on the speed of tumor formation and potential mechanisms. In the xenograft experiment, FIGNL1 knockdown led to delayed tumor formation compared with that in mice injected with $\mathrm{H} 1299$ shCtrl $(\mathrm{P}<0.05)$. As illustrated in Fig. 11, the long diameter of the tumors for the tenth timepoint (day 25) was observed and ranged from 0 to $6.98 \mathrm{~mm}$ compared with 8 to $11.77 \mathrm{~mm}$ in the control group, while the short diameters ranged from 0 to $4.53 \mathrm{~mm}$ compared with 
Table VII. Statistical analysis for cell cycle distribution following FIGNL1 knockdown.

A, Cell cycle analysis for the H1299 cell line

\begin{tabular}{lccc}
\hline Stage & shCtrl & shFIGNL1-2 & P-value \\
\hline $\mathrm{G}_{1}, \%$ & $38.82 \pm 0.60$ & $43.63 \pm 1.54$ & $0.0154^{\mathrm{a}}$ \\
$\mathrm{S}, \%$ & $26.53 \pm 1.51$ & $21.79 \pm 1.98$ & $0.0216^{\mathrm{a}}$ \\
$\mathrm{G}_{2} / \mathrm{M}, \%$ & $34.65 \pm 1.09$ & $31.21 \pm 1.75$ & $0.1466^{\mathrm{b}}$ \\
\hline
\end{tabular}

B, Cell cycle analysis for the A549 cell line

\begin{tabular}{lcrr}
\hline Stage & shCtrl & shFIGNL1-1 & P-value \\
\hline $\mathrm{G}_{1}, \%$ & $41.16 \pm 1.97$ & $56.57 \pm 0.90$ & $0.0023^{\mathrm{c}}$ \\
$\mathrm{S}, \%$ & $27.17 \pm 1.74$ & $18.4 \pm 3.42$ & $0.0994^{\mathrm{b}}$ \\
$\mathrm{G}_{2} / \mathrm{M}, \%$ & $31.67 \pm 0.54$ & $24.98 \pm 4.01$ & $0.0958^{\mathrm{b}}$
\end{tabular}

${ }^{\mathrm{a}} \mathrm{P}<0.05$. ${ }^{\mathrm{b}}$ Non-significant. ${ }^{\mathrm{c}} \mathrm{P}<0.01$. sh, short hairpin; Ctrl, control; FIGNL1, fidgetin like 1.

Table VIII. Statistical analysis of cell cycle distribution following FIGNL1 overexpression.

A, Cell cycle analysis for the H1299 cell line

\begin{tabular}{llll}
\hline Stage & FIGNL1 NC & FIGNL1 OE & P-value \\
\hline $\mathrm{G}_{1}, \%$ & $66.47 \pm 0.82$ & $58.04 \pm 0.90$ & $0.0003^{\mathrm{a}}$ \\
$\mathrm{S}, \%$ & $15.67 \pm 1.03$ & $12.39 \pm 1.46$ & $0.1081^{\mathrm{b}}$ \\
$\mathrm{G}_{2} / \mathrm{M}, \%$ & $17.86 \pm 0.92$ & $29.57 \pm 2.35$ & $0.0013^{\mathrm{c}}$ \\
\hline
\end{tabular}

B, Cell cycle analysis for the A549 cell line

\begin{tabular}{llll}
\hline Stage & FIGNL1 NC & FIGNL1 OE & P-value \\
\hline $\mathrm{G}_{1}, \%$ & $48.96 \pm 2.50$ & $42.52 \pm 0.50$ & $0.0120^{\mathrm{d}}$ \\
$\mathrm{S}, \%$ & $27.05 \pm 1.83$ & $29.34 \pm 2.53$ & $0.2728^{\mathrm{b}}$ \\
$\mathrm{G}_{2} / \mathrm{M}, \%$ & $23.99 \pm 1.16$ & $28.14 \pm 2.42$ & $0.0556^{\mathrm{b}}$ \\
\hline
\end{tabular}

${ }^{\mathrm{a}} \mathrm{P}<0.001$. ${ }^{\mathrm{b}} \mathrm{Non}$-significant. ${ }^{\mathrm{c}} \mathrm{P}<0.01,{ }^{\mathrm{d}} \mathrm{P}<0.05$. NC, negative control; OE, overexpression; FIGNL1, fidgetin like 1.

7.45 to $11.18 \mathrm{~mm}$ in the control group. No significant weight loss was observed in the animals, and the percentages of the weight increase ranged from 12.49 to $47.34 \%$ compared with 25.43 to $40.53 \%$ in the control group. These effects could be associated with the role of FIGNL1 in promoting proliferation. To investigate the underlying mechanisms of this hypothesis, a cDNA microarray analysis in H1299 knockdown cells was performed. A total of 754 DEGs (out of 28,311 genes detected) were identified, of which 563 and 191 were up- and downregulated, respectively (Fig. 12A). In addition, among the downregulated DEGs, numerous processes were inhibited as shown in Fig. 12C and D. KEGG enrichment analysis

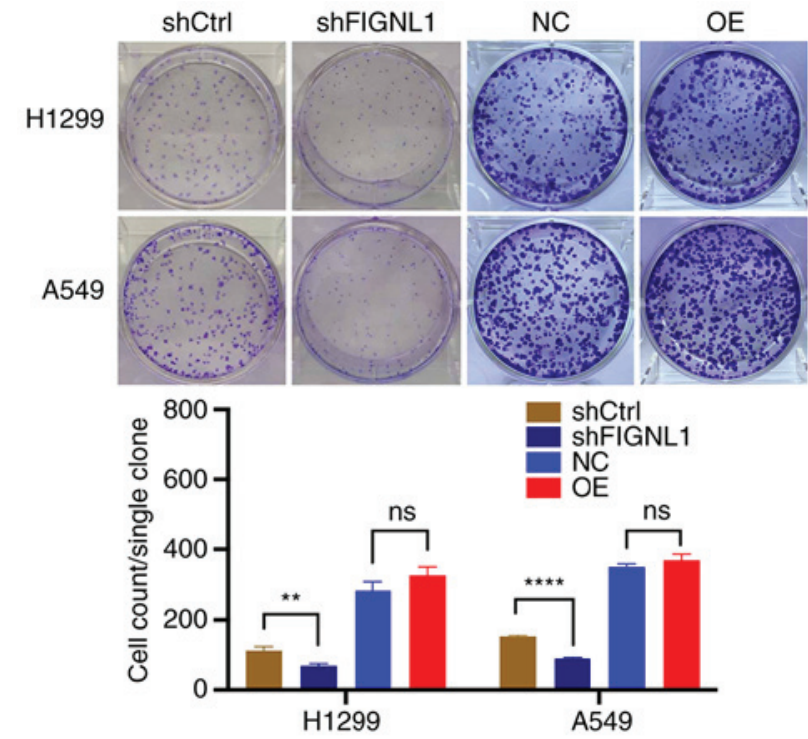

Figure 7. Changes in single clone forming abilities following knockdown and overexpression of FIGNL1 in the H1299 and A549 cell lines. FIGNL1 knockdown decreased colony formation ability, while there was no significant difference following overexpression of FIGNL1. $\mathrm{n}=3 .{ }^{* *} \mathrm{P}<0.01,{ }^{* * * * *} \mathrm{P}<0.0001$. FIGNL1 knockdown using shFIGNL1-2 in H1299 cells and shFIGNL1-1 in A549 cells. NC, negative control; OE, overexpression; sh, short hairpin; Ctrl, control; ns, non-significant; FIGNL1, fidgetin-like 1.

indicated that knockdown of FIGNL1 may lead to attenuated biological processes, as the enriched pathways among the downregulated genes were cellular proliferation-related processes, such as DNA replication and cell cycle, as shown in Fig. 12C. From the bioinformatics analysis, there was significant decrease in the protein expression levels of proliferating cell nuclear antigen $(P C N A)$, mini-chromosome maintenance complex component $(M C M)-2$ and -4 , S-phase kinase associated protein 2 (SKP2); therefore, the expression of these proteins were determined at the transcriptional and translational levels to verify the data with the microarray results. As shown in Fig. 13, changes in the protein expression level of PCNA, MCM2 and SKP2 were consistent with the results of RT-qPCR and microarray analysis; the only exception was MCM4.

\section{Discussion}

Several animal studies have shown the crucial role of FIGNL1 in developmental morphogenesis; in addition, dysregulation of FIGNL1 may lead to numerous diseases, such as congenital heart disease (29) and cancer (18). However, the role of FIGNL1 in tumorigenesis has not been well-characterized, particularly with respect to lung carcinoma. In the present study, microarray analysis of FIGNL1 knockdown cells suggested that FIGNL1 may be associated with tumorigenesis in the lungs. Results from RT-qPCR showed increased mRNA expression level of FIGNL1 in the H1299 and A549 lung cancer cell lines. These findings indicated that FIGNL1 promoted cell proliferation; however, the underlying mechanisms are not well-known. Thus, several experiments were performed using the H1299 and A549 lung cancer cell lines, as FIGNL1 mRNA and protein expression level was relatively stable in 
Table IX. Changes in cell apoptosis following knockdown or overexpression of FIGNL1.

\begin{tabular}{lccccccc}
\hline & \multicolumn{3}{c}{ shRNA } & & \multicolumn{3}{c}{ Overexpression } \\
\cline { 2 - 3 } Cell line & shCtrl & shFIGNL1 & P-value & & FIGNL1 NC & FIGNL1 OE & P-value \\
\hline H1299 & $5.45 \pm 1.18$ & $15.1 \pm 1.39^{\mathrm{a}}$ & $0.0005^{\mathrm{b}}$ & & $3.17 \pm 0.14$ & $2.24 \pm 0.18$ & $0.0020^{\mathrm{b}}$ \\
A549 & $6.23 \pm 0.24$ & $15.83 \pm 1.00^{\mathrm{c}}$ & $0.0039^{\mathrm{d}}$ & & $1.22 \pm 0.06$ & $0.597 \pm 0.122$ & $0.0014^{\mathrm{b}}$ \\
\hline
\end{tabular}

Data are presented as the percentage $\pm \mathrm{SD}$. ${ }^{\mathrm{a}}$ Transfected with shFIGNL1-2. ${ }^{\mathrm{b}} \mathrm{P}<0.001 .{ }^{\mathrm{c}}$ Transfected with shFIGNL1-1. ${ }^{\mathrm{d}} \mathrm{P}<0.01 . \mathrm{NC}$, negative control; OE, overexpression; FIGNL1, fidgetin like 1; sh, short hairpin.
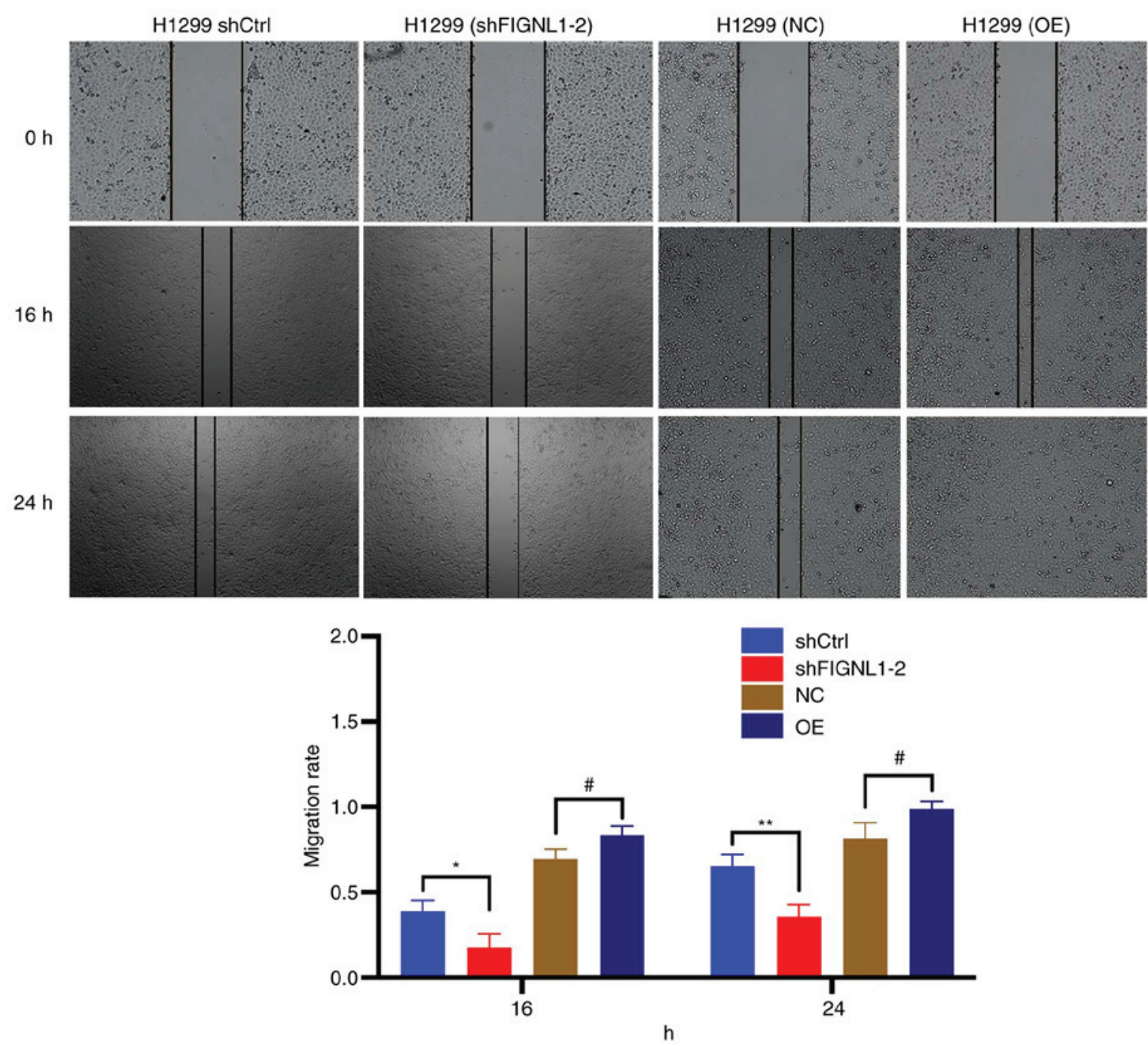

Figure 8. Effects of FIGNL1 knockdown and overexpression on wound healing ability in the H1299 cell line. Knockdown of FIGNL1 significantly reduced migration ability of the cells, while FIGNL1 overexpression increase migration compared with that in the respective negative control groups. ${ }^{*}, \mathrm{P}<0.05$, ${ }^{* *} \mathrm{P}<0.01$. n=3. NC, negative control; OE, overexpression; sh, short hairpin; Ctrl, control; FIGNL1, fidgetin-like 1.

these cell lines; therefore, they were more suitable for RNA interference. FIGNL1 knockdown was found to inhibit cell proliferation, and increased cell death. Increased arrest of cells in the $\mathrm{G}_{1}$ stage reduced the rate of proliferation, while the concomitant knockdown of FIGNL1 expression resulted in more cell death. FIGNL1 was also found to affect fission ability of cells, wound healing, mobility and invasion, as indicated by colony formation, wound healing, Transwell and
Matrigel assays, respectively. Thus, we hypothesized that this was caused by the knockdown of FIGNL1, as suggested by the cDNA microarray experiment (Fig. 12).

FIGNL1 is a conserved member of AAA ATPase protein superfamily, which maintains the structural stability of microtubules in cells, using the chemical energy obtained from hydrolysis of ATP $(16,17)$. It drives multiple essential cellular activities, such as protein unfolding and degradation, 

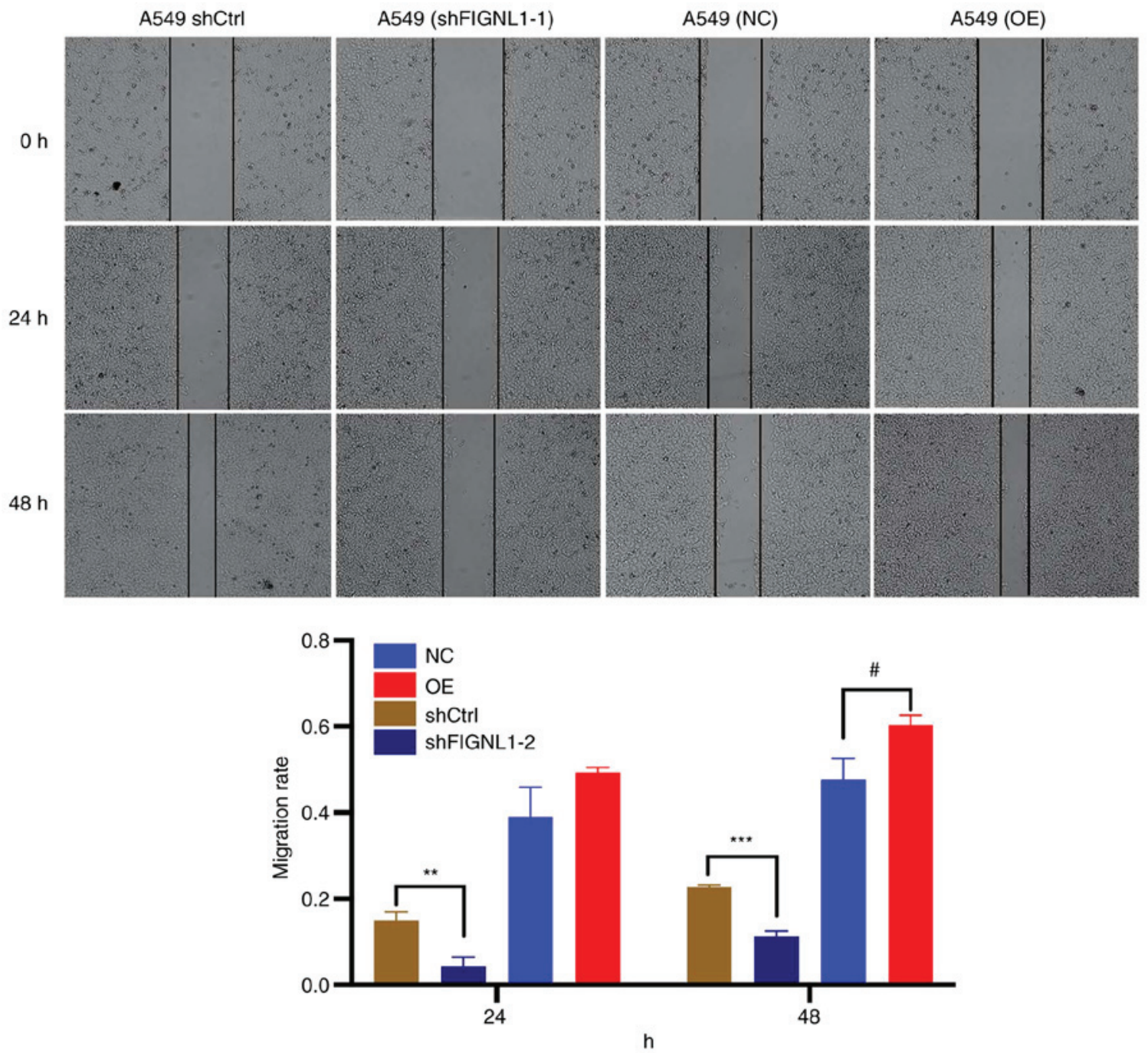

Figure 9. Effects of FIGNL1 knockdown and overexpression on wound healing ability in the A549 cell line. Knockdown of FIGNL1 significantly reduced migration ability of the cells, while FIGNL1 overexpression increased migration compared with that in the respective negative control groups. ${ }^{\text {P }}<0.05$, ${ }^{* *} \mathrm{P}<0.01,{ }^{* * *} \mathrm{P}<0.001 . \mathrm{n}=3$. NC, negative control; OE, overexpression; sh, short hairpin; Ctrl, control; FIGNL1, fidgetin-like 1.

membrane fusion, nucleosome remodeling, and microtubule severing $(13,15,30)$. Thus, changes in FIGNL1 expression may lead to alterations in cell growth. Thus, cDNA microarray analysis was performed to predict the potential downstream targets. PCNA, MCM -2 and -4 , and SKP2 were identified as potential targets for FIGNL1; these have been identified as cancer-related genes. $P C N A$ is a conserved acidic protein synthesized in the S stage of the cell cycle (31); it is essential for chromosomal DNA replication in eukaryotic cell nucleus (32). It primarily serves as a cyclin or auxiliary protein of DNA polymerase $\delta$ and DNA polymerase $\varepsilon(31,32)$ and plays an important role in regulating cell cycle events $(33,34)$ and was associated with NSCLC (35). Discovering PCNA as an underlying target of FIGNL1 may provide details of the mechanisms of cell cycle changes induced by FIGNL1 knockdown; however further investigation is required. Another key regulator during $\mathrm{S}$ phase is oncogene $S K P 2$ (also known as $p 45$ or FBXL1), which belongs to the F-box protein family (36-39). This gene has been found to participate in the regulation of numerous signal transduction pathways, such as ubiquitination dependent proteolysis process and cell cycle control $(36,37)$. A recent study showed that $S K P 2$ also participates in DNA-damage repair, triggered by ubiquitination dependent proteolysis and cell cycle control processes (40). In addition, SKP2 genomic mutations were shown to induce lung cancer cell death (41). MCM2 and MCM4 are potential therapeutic targets for NSCLC $(42,43)$; these were shown to be associated with the duration of the $G_{1}$ phase in the cell cycle and were the key regulatory components for DNA replication. Increase in MCM protein expression was found to induce NSCLC tumor formation, progression and malignant transformation (44). Due to these distinctions, the MCM complex family has been considered as a valuable proliferation marker in numerous types of cancers. In lung cancer (44), MCM2 and MCM4 was associated with cell proliferation, cell cycle arrest, TP53-dependent apoptosis, and Aurora B pathway (45). However, MCM4 protein expression level was not consistent with the results from RT-qPCR (Fig. 13B); this suggested that FIGNL1 knockdown may not alter MCM4 protein expression level.

In the present study, knockdown of FIGNL1 induced notable changes in cell behavior, which could be the result of 


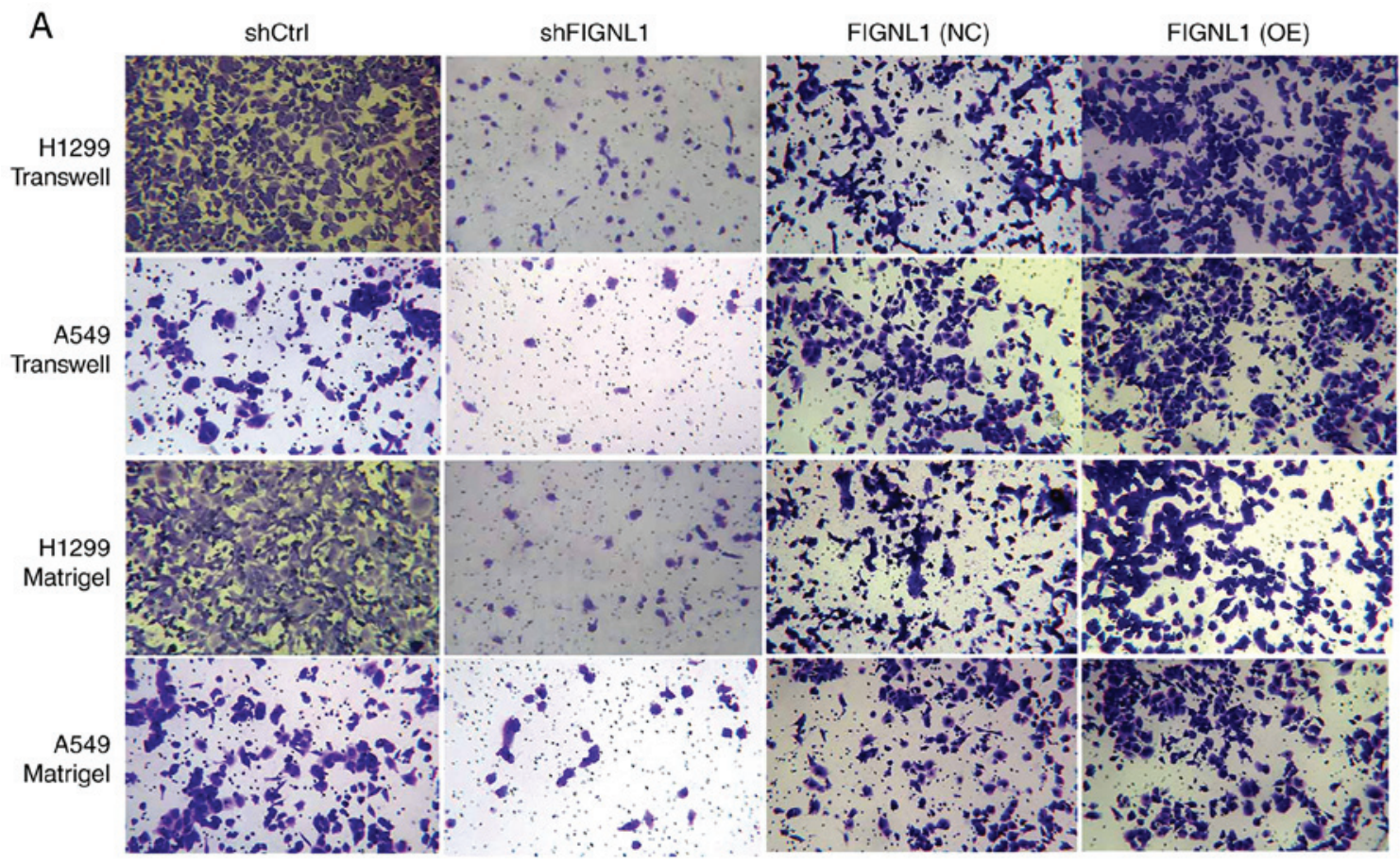

B

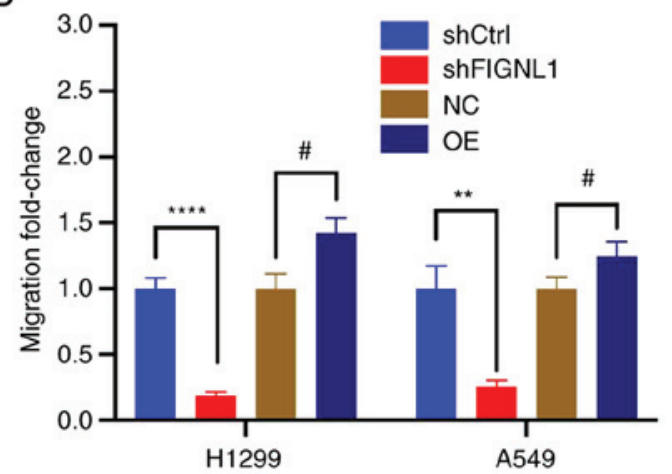

C

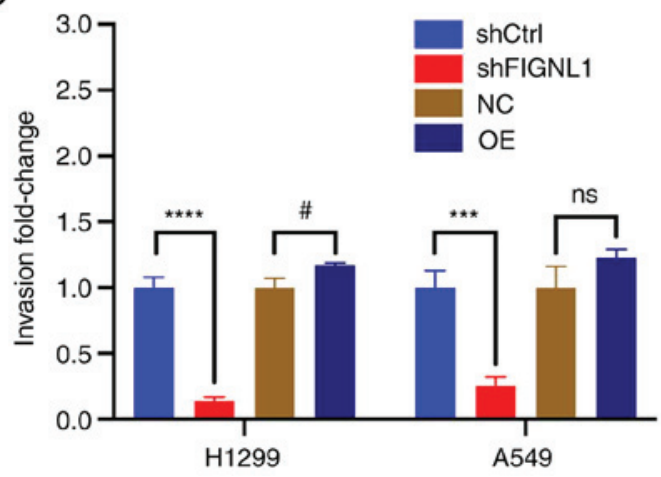

Figure 10. (A) Representative images of Transwell and Matrigel assays showing the effect of FIGNL1 knockdown and overexpression on cell migration and invasion abilities, respecitvely and the results were subsequently (B and C) quantified. In both experiments, knockdown of FIGNL1 significantly reduced the ability of cells to migrate and invade. ${ }^{\#} \mathrm{P}<0.05,{ }^{* *} \mathrm{P}<0.01,{ }^{* * * *} \mathrm{P}<0.001,{ }^{* * * * *} \mathrm{P}<0.0001 . \mathrm{n}=3$. FIGNL1 knockdown using shFIGNL1-2 in H1299 cells and shFIGNL1-1 in A549 cells. NC, negative control; OE, overexpression; sh, short hairpin; Ctrl, control; FIGNL1, fidgetin-like 1.

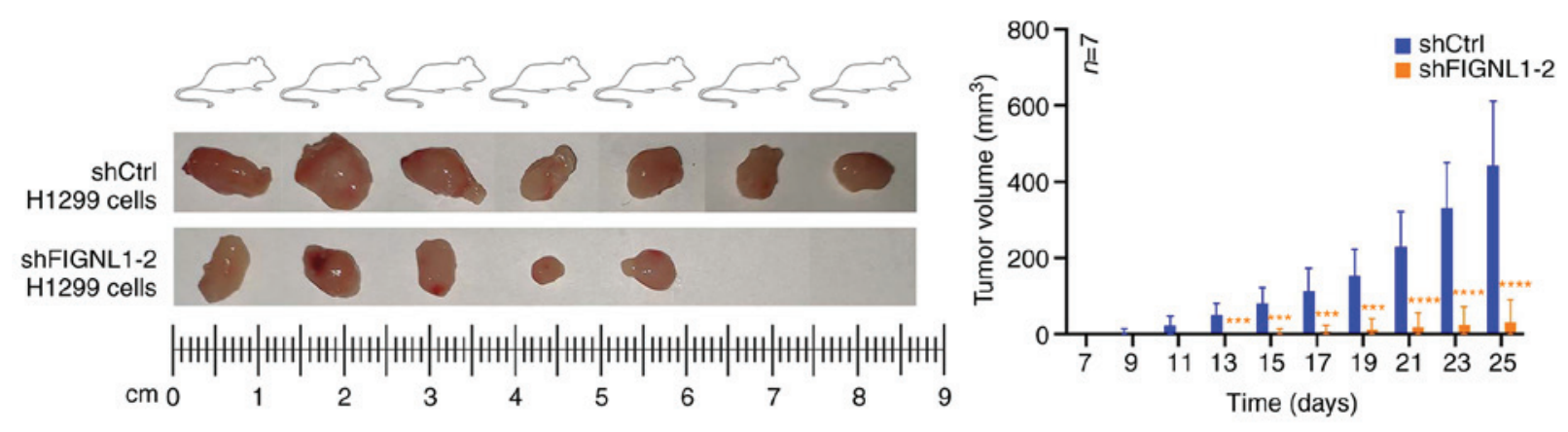

Figure 11. Effect of FIGNL1 knockdown on in vivo tumor formation. BALB/c nude mice were divided into two groups: One group were injected with shCtrl H1299 cells, while the other group were injected with shFIGNL1-2 H1299 cells. The statistical graph indicated that compared with that in the mice injected with shCtrl, FIGNL1 knockdown significantly reduced the formation of the tumor from day $13{ }^{*{ }^{* * *}} \mathrm{P}<0.001,{ }^{* * * * *} \mathrm{P}<0.0001$. $\mathrm{n}=7$. sh, short hairpin; Ctrl, control; FIGNL1, fidgetin-like 1.

the reduced number of DEGs involved in DNA replication, as identified from the cDNA microarray analysis. Therefore, the changes observed as a result of FIGNL1 knocked-down cells may be attributable to the changes in the status of the downstream targets, such as PCNA, MCM complexes and $S K P 2$. As aforementioned, these three regulators merit further 
A

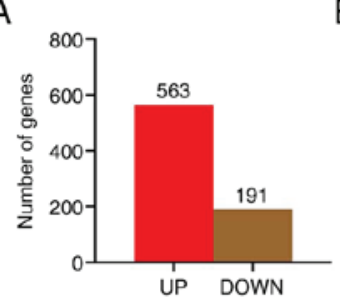

B

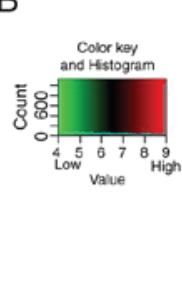

D
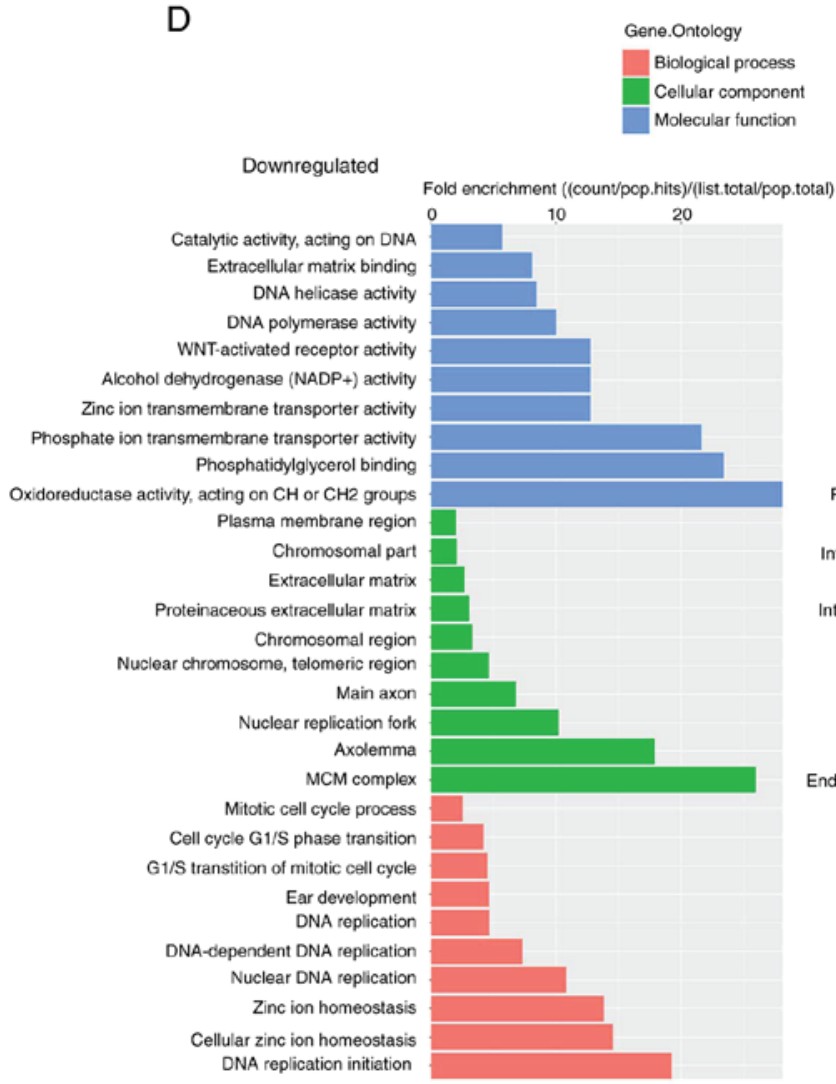

C

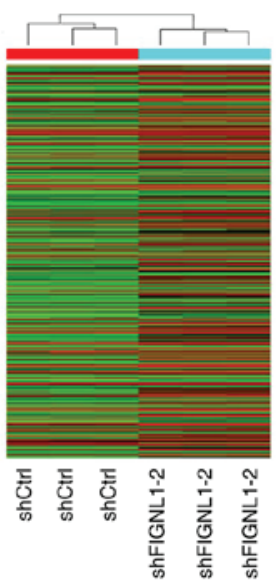

Dowrregulated
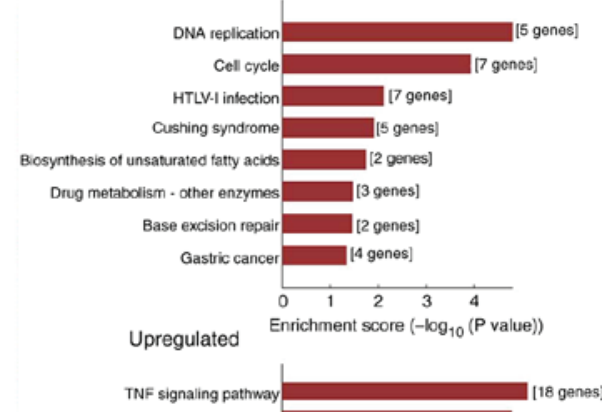

NOD-like receptor signaling pathway [21 genes] Infuenze A [21 genes]

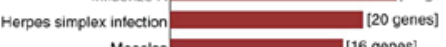
Moasice [16 genes]

IL-17 signaling pathway $[$ [11 genes]

Hepatis $\mathrm{C}$

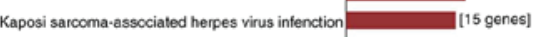

Toll-like receptor signaling pathway [11 genes]

Protoin procossing in ondoplasmic reticulum [1 14 genes]

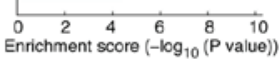

Upregulated

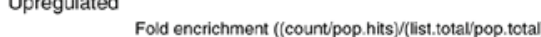

Fold encrichment ((countipop.hits)/(list.total/pop.tcta)
Identical protein binding
Double-stranded DNA binding

Receptor regulator activity

Cytokine receptor binding

Double-stranded RNA binding

Chemokine receptor binding

Chemokine activity

Adenylyttransferase activity

XCR chemokine receptor binding

Peptide disulfide oxidoreductase activity
Plasma membrane part

Integral component of plasma membrane

Endoplasmic reticulum part

Intrinsic component of plasma membrane

Cell surtace

Endoplasmic reticulum lumen

Pigment granule

Melanosome

Smooth endoplasimic reticulum

Endoplasmic reticulum chaperone complex

Defense response

Response to cytokine

Response to biotic stimulus

Response to external biotic stimulus

Response to other organism

Cytokine-mediated signaling pathway

Defense response to virus Response to virus

Cellular response to type I interferon

Type I interferon signaling pathway

Figure 12. cDNA microarray analysis between control and knockdown H1299 cells. (A) Differentially expressed genes in the knockdown H1299 cells. (B) Heatmap of the differentially expressed genes in the H1299 knockdown cells. The red color indicates differentially expressed genes with high expression, while the green color indicates low expression. (C) KEGG analysis of the down (upper) and upregulated genes (lower). (D) Gene Ontology analysis of the down-(left) and upregulated genes (right). KEGG, Kyoto Encyclopedia of Genes and Genomes; FIGNL1, fidgetin-like 1.
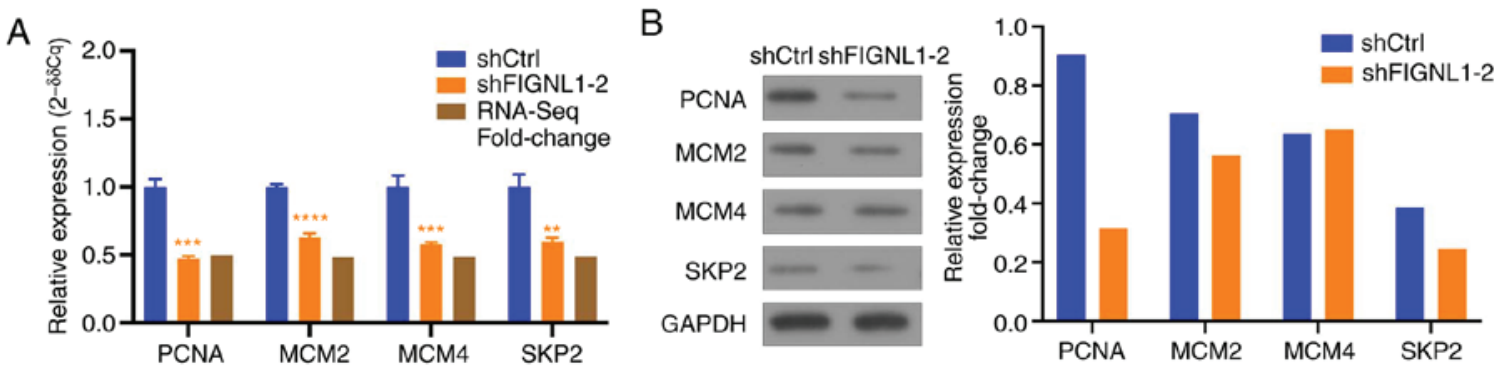

Figure 13. RT-qPCR and western blot analysis of mRNA and protein expression level for the genes identified from the microarray results. (A) RT-q PCR quantification and (B) western blot grayscale image and expression analysis of the selected downregulated genes. ${ }^{* *} \mathrm{P}<0.01,{ }^{* * * *} \mathrm{P}<0.001,{ }^{* * * * *} \mathrm{P}<0.0001 . \mathrm{n}=3$. sh, short hairpin; Ctrl, control, RT-qPCR, reverse transcription-quantitative PCR; PCNA, proliferating cell nuclear antigen; $M C M$, mini-chromosome maintenance complex component, SKP2, S-phase kinase associated protein 2; FIGNL1, fidgetin-like 1. 
investigation, as the changes in their expression level were consistent with their biological functions, in addition to cell behavior changes documented in the morphotype research. Therefore, the effect of FIGNL1 on lung cancer cell proliferation may be induced by the reduced expression of FIGNL1. The present study found an important biological role of FIGNL1 in regulating cell proliferation and apoptosis and lays a foundation for further investigation into its biological impacts; however, the underlying mechanisms by which FIGNL1 regulates cell survival and the mechanism, by which it modulates its downstream targets, and thus exerts its effects on DNA replication, requires further investigation.

\section{Acknowledgements}

Not applicable.

\section{Funding}

The present study was supported by the Natural Science Foundation of Anhui Province (grant no. 1708085MH210) and financial support was provided by the National Key Clinical Specialty Discipline Construction Program of China (grant no. 2012-649).

\section{Availability of data and materials}

The datasets used and/or analyzed during this study are available from the corresponding author on reasonable request.

\section{Authors' contributions}

LH designed the study. LH and ML designed and performed immunohistochemistry experiments. ML, YR, WP, $\mathrm{JH}, \mathrm{AJ}$, and ZY designed, performed, and analyzed the cell biology experiments. ML and YR designed and performed the xenograft study. ML and WP performed the statistical analysis. ML, YR, WP, and JH wrote the paper. All authors approved the final version of the manuscript.

\section{Ethics approval and consent to participate}

The animal experiments were approved by the Animal Ethics Committee at the Bengbu Medical College. The collection of the clinical samples was performed under the supervision of Institutional Review Boards of the First Affiliated Hospital of Bengbu Medical College (approval no. BYYFY-2017.KY05). All patients provided written informed consent to provide their tumor tissues for further study, according to the Declaration of Helsinki.

\section{Patient consent for publication}

Written informed consent was obtained from the patients and their relatives.

\section{Competing interests}

The authors declare that they have no competing interests.

\section{References}

1. Bray F, Ferlay J, Soerjomataram I, Siegel RL, Torre LA and Jemal A: Global cancer statistics 2018: GLOBOCAN estimates of incidence and mortality worldwide for 36 cancers in 185 countries. CA Cancer J Clin 68: 394-424, 2018.

2. Zheng M: Classification and pathology of lung cancer. Surg Oncol Clin N Am 25: 447-468, 2016.

3. Xu J, Yang H, Jin B, Lou Y, Zhang Y, Zhang X, Zhong H, Wang H, Wu D and Han B: EGFR tyrosine kinase inhibitors versus chemotherapy as first-line therapy for non-small cell lung cancer patients with the L858R point mutation. Sci Repo 6: 38270, 2016.

4. Burotto M, Manasanch EE, Wilkerson J and Fojo T: Gefitinib and erlotinib in metastatic non-small cell lung cancer: A meta-analysis of toxicity and efficacy of randomized clinical trials. Oncologist 20: 400-410, 2015.

5. Rui Y, Peng WJ, Wang M, Wang Q, Liu ZL, Chen YQ and Huang LN: HIST1H3D: A promising therapeutic target for lung cancer. Int J Oncol 50: 815-822, 2017.

6. Jenuwein $\mathrm{T}$ and Allis CD: Translating the histone code. Science 293: 1074-1080, 2001.

7. Rheinbay E, Louis DN, Bernstein BE and Suvà ML: A tell-tail sign of chromatin: Histone mutations drive pediatric glioblastoma. Cancer Cell 21: 329-331, 2012.

8. Turner BM: Cellular memory and the histone code. Cell 111: 285-291, 2002.

9. Iwaya T,Fukagawa T, Suzuki Y, Takahashi Y,Sawada G, Ishibashi M, Kurashige J, Sudo T, Tanaka F, Shibata K, et al: Contrasting expression patterns of histone mRNA and microRNA 760 in patients with gastric cancer. Clin Cancer Res 19: 6438-6449, 2013.

10. Austin TO, Matamoros AJ, Friedman JM, Friedman AJ, Nacharaju P, Yu W, Sharp DJ and Baas PW: Nanoparticle delivery of fidgetin siRNA as a Microtubule-based therapy to augment nerve regeneration. Sci Rep 7: 9675, 2017.

11. Park SJ, Kim SJ, Rhee Y, Byun JH, Kim SH, Kim MH, Lee EJ and Lim SK: Fidgetin-like 1 gene inhibited by basic fibroblast growth factor regulates the proliferation and differentiation of osteoblasts. J Bone Miner Res 22: 889-896, 2007.

12. Schraenen A, de Faudeur G, Thorrez L, Lemaire K, Van Wichelen G, Granvik M, Van Lommel L, In't Veld P and Schuit F: mRNA expression analysis of cell cycle genes in islets of pregnant mice. Diabetologia 53: 2579-2588, 2010.

13. Hanson PI and Whiteheart SW: AAA+ proteins: Have engine, will work. Nat Rev Mol Cell Biol 6: 519-529, 2005.

14. Zhao X, Jin M, Wang M, Sun L, Hong X, Cao Y and Wang C: Fidgetin-like 1 is a ciliogenesis-inhibitory centrosome protein. Cell Cycle 15: 2367-2375, 2016.

15. Snider $J$ and Houry WA: AAA+ proteins: Diversity in function, similarity in structure. Biochem Soc Trans 36: 72-77, 2008.

16. Martin J and Lupas A: AAA-ATPases. In: Encyclopedia of Biological Chemistry. 2nd edition. Academic Press, pp1-6, 2013.

17. Bar-Nun S and Glickman MH: Proteasomal AAA-ATPases: Structure and function. Biochim Biophys Acta 1823: 67-82, 2012.

18. Yuan $\mathrm{J}$ and Chen J: FIGNL1-containing protein complex is required for efficient homologous recombination repair. Proc Natl Acad Sci USA 110: 10640-10645, 2013.

19. Hu Z, Feng J, Bo W, Wu R, Dong Z, Liu Y, Qiang L and Liu M: Fidgetin regulates cultured astrocyte migration by severing tyrosinated microtubules at the leading edge. Mol Biol Cell 28: 545-553, 2017.

20. Tao J, Feng C and Rolls MM: The microtubule-severing protein fidgetin acts after dendrite injury to promote their degeneration. J Cell Sci 129: 3274-3281, 2016.

21. Leo L, Yu W, D'Rozario M, Waddell EA, Marenda DR, Baird MA, Davidson MW, Zhou B, Wu B, Baker L, et al: Vertebrate fidgetin restrains axonal growth by severing labile domains of microtubules. Cell Rep 12: 1723-1730, 2015.

22. L'Hote D, Vatin M, Auer J, Castille J, Passet B, Montagutelli X, Serres $C$ and Vaiman D: Fidgetin-likel is a strong candidate for a dynamic impairment of male meiosis leading to reduced testis weight in mice. PLoS One 6: e27582, 2011.

23. Truslove MG: The anatomy and development of the fidget mouse. J Genet 54: 64, 1956.

24. Ma J, Li J, Yao X, Lin S, Gu Y, Xu J, Deng Z, Ma W and Zhang H: FIGNL1 is overexpressed in small cell lung cancer patients and enhances NCI-H446 cell resistance to cisplatin and etoposide. Oncol Rep 37: 1935-1942, 2017.

25. Detterbeck FC, Boffa DJ, Kim AW and Tanoue LT: The edition lung cancer stage classification. Chest 151: 193-203, 2016. 
26. Livak KJ and Schmittgen TD: Analysis of relative gene expression data using real-time Quantitative PCR and the 2(-Delta Delta C(T)) method. Method 25: 402-408, 2002.

27. Ashburner M, Ball CA, Blake JA, Botstein D, Butler H, Cherry JM, Davis AP, Dolinski K, Dwight SS, Eppig JT, et al: Gene ontology: Tool for the unification of biology. The Gene Ontology Consortium. Nat Genet 25: 25-29, 2000.

28. The Gene Ontology Consortium: The Gene Ontology Resource: 20 years and still GOing strong. Nucleic Acids Res 47: D330-D338, 2019.

29. Wang D, Chu M, Wang F, Zhou A, Ruan M and Chen Y: A Genetic variant in FIGN gene reduces the risk of congenital heart disease in Han Chinese populations. Pediatr Cardiol 38: 1169-1174, 2017.

30. Lupas AN and Martin J: AAA proteins. Curr Opin Struct Biol 12: 746-753, 2002

31. Fontanini G, Macchiarini P, Pepe S, Ruggiero A, Hardin M, Bigini D, Vignati S, Pingitore R and Angeletti CA: The expression of proliferating cell nuclear antigen in paraffin sections of peripheral, node-negative non-small cell lung cancer. Cancer 70: 1520-1527, 1992.

32. Jackson P, Ridgway P, Rayner J, Noble J and Braithwaite A: Transcriptional regulation of the PCNA promoter by $\mathrm{p} 53$. Biochem Biophys Res Commun 203: 133-140, 1994.

33. Chiang CP, Lang MJ, Liu BY, Wang JT, Leu JS, Hahn LJ and Kuo MY: Expression of proliferating cell nuclear antigen (PCNA) in oral submucous fibrosis, oral epithelial hyperkeratosis and oral epithelial dysplasia in Taiwan. Oral Oncol 36: 353-359, 2000.

34. Srinivasan M and Jewell SD: Quantitative estimation of PCNA, c-myc, EGFR and TGF-alpha in oral submucous fibrosis-an immunohistochemical study. Oral Oncol 37: 461-467, 2001.

35. Fan J, Zhou X, Huang J, Wang X and Che G: Prognostic roles of PCNA expressions in non-small cell lung cancer: A metaanalysis. Int J Clin Exp Med 9: 5655-5665, 2016.

36. Craig KL and Tyers M: The F-box: A new motif for ubiquitin dependent proteolysis in cell cycle regulation and signal transduction. Prog Biophys Mol Biol 72: 299-328, 1999.

37. Bai C, Sen P, Hofmann K, Ma L, Goebl M, Harper JW and Elledge SJ: SKP1 connects cell cycle regulators to the ubiquitin proteolysis machinery through a novel motif, the F-box. Cell 86: 263-274, 1996
38. Sutterlüty H, Chatelain E, Marti A, Wirbelauer C, Senften M, Müller U and Krek W: p45SKP2 promotes p27Kip1 degradation and induces S phase in quiescent cells. Nat Cell Biol 1: 207-214, 1999.

39. Zhang H, Kobayashi R, Galaktionov K and Beach D: p19Skp1 and p45Skp2 are essential elements of the cyclin A-CDK2 S phase kinase. Cell 82: 915-925, 1995.

40. Wu J, Zhang X, Zhang L, Wu CY, Rezaeian AH, Chan $\mathrm{CH}$, Li JM, Wang J, Gao Y, Han F, et al: Skp2 E3 ligase integrates ATM activation and homologous recombination repair by ubiquitinating NBS1. Mol Cell 46: 351-361, 2012.

41. Yokoi S, Yasui K, Iizasa T, Takahashi T, Fujisawa T and Inazawa J: Down-regulation of SKP2 induces apoptosis in lung-cancer cells. Cancer Sci 94: 344-349, 2003.

42. Han J, Lian M, Fang J, Liu H, Wang R, Zhai J, Fan Yang Y, Fen L, Shi Q, Zhi Ma H, et al: Minichromosome maintenance (MCM) protein 4 overexpression is a potential prognostic marker for laryngeal squamous cell carcinoma. J BUON 22: 1272-1277, 2017.

43. Yang J, Ramnath N, Moysich KB, Asch HL, Swede H, Alrawi SJ, Huberman J, Geradts J, Brooks JS and Tan D: Prognostic significance of MCM2, Ki-67 and gelsolin in non-small cell lung cancer. BMC Cancer 6: 203, 2006.

44. Zhang X, Teng Y, Yang F, Wang M, Hong X, Ye LG, Gao YN and Chen GY: MCM2 is a therapeutic target of lovastatin in human non-small cell lung carcinomas. Oncol Rep 33: 2599-2605, 2015.

45. Liu K, Kang M, Liao X and Wang R: Genome-wide investigation of the clinical significance and prospective molecular mechanism of minichromosome maintenance protein family genes in patients with Lung Adenocarcinoma. PLoS One 14: e0219467, 2019. International (CC BY-NC-ND 4.0) License. 